\title{
V. Der polnisch-sowjetische Partisanenkrieg in der Oblast' Baranovići
}

\section{Einleitung}

Auf dem Territorium der Oblast' Baranoviči war auch die polnische Untergrundbewegung aktiv. Es handelte sich dabei um den Bund für den bewaffneten Kampf (Związek Walki Zbrojnej, künftig: ZWZ), im Frühjahr 1942 umbenannt in „Heimatarmee" (Armia Krajowa, künftig: AK). ${ }^{1}$ Die Anfänge der polnischen Untergrundbewegung in der Region gehen auf die sowjetische Besatzung während der Zeit von 1939 bis 1941 zurück. Die ZWZ-Führung unternahm bereits früh Versuche, ihre Strukturen in der ehemaligen Wojewodschaft Nowogródek (Oblast' Baranoviči) aufzubauen, jedoch ohne größeren Erfolg. Dafür entstanden spontan zahlreiche Untergrundorganisationen, die sich aus Angehörigen der polnischen Intelligenz, Reserveoffizieren sowie akademischer und gymnasialer Jugend zusammensetzten. Die meisten dieser Organisationen wurden jedoch bald vom NKVD zerstört, ihre Mitglieder entweder inhaftiert oder deportiert. Es entstanden auch mehrere kleine polnische Partisanengruppen; mindestens zwei von ihnen überlebten in den Wäldern bis zum Sommer 1941.2

Nachdem die Oblast' Baranoviči von der Wehrmacht im Sommer 1941 besetzt worden war, unternahm die Führung des ZWZ erneut Versuche, die bestehenden Untergrundstrukturen $\mathrm{zu}$ reorganisieren und sie weiter auszubauen. Im Herbst 1941 traf der neue Kommandeur des ZWZ im Bezirk Nowogródek, Major JanusZ Szlaski „Prawdzic“, in der Region ein. Im Jahre 1942 gelang es ihm, eine ZWZ-AK Untergrundorganisation mit Bezirkskommandantur und regionalen Strukturen (Kreise, Kompanien, Züge, Feldwachen [Placówki]) aufzubauen. Die Strukturen des ZWZ-AK wurden in Anlehnung an den Verwaltungsaufbau der Wojewodschaft Nowogródek aus der Vorkriegszeit errichtet.

Am Anfang der deutschen Besatzung wurden keine polnischen Partisaneneinheiten gebildet. Einerseits waren die Strukturen dazu noch zu schwach entwickelt, andererseits hätte dies gegen die ausdrücklichen Befehle des Oberbefehlshabers der

1 Über die Entstehung des ZWZ-AK und seine Gliederung vgl. Grzegorz Mazur, Der „Bund für den bewaffenten Kampf - Heimatarmee" und seine Gliederung, in: Die polnische Heimatarmee. Geschichte und Mythos der Armia Krajowa seit dem Zweiten Weltkrieg, hrsg. von Bernhard Chiari, München 2003, S. 111-150.

2 Vgl. Wacław Nowicki, Żywe Echa, Warszawa 1993; Boradyn, Niemen rzeka niezgody, S. 58-89; vgl. auch Kazimierz Krajewski, Der Bezirk Nowogródek der Heimatarmee. Nationalitätenkonflikte und politische Verhältnisse 1939-1945, in: Chiari (Hrsg.), Die polnische Heimatarmee, S. 563-584. 
Polnischen Streitkräfte, General Władysław Sikorski, und der ZWZ-AK Hauptkommandantur verstoßen. ${ }^{3}$ Dessen ungeachtet entstand im Sommer 1942 in der Region die erste polnische Partisaneneinheit. Der Grund dafür lag im wachsenden deutschen Terror und dem Verhalten sowjetischer Partisanen und krimineller Banden, die gegen die Zivilbevölkerung immer brutaler und rücksichtsloser vorgingen. ${ }^{4}$

$\mathrm{Ab}$ Frühjahr 1943 entwickelten sich die Strukturen der Heimatarmee dynamischer. Anfang Juli 1944 zählten ihre Einheiten etwa 8000 Angehörige. ${ }^{5}$ Diese Kräfte wurden in Bataillone und Schwadronen aufgeteilt, ab Frühjahr 1944 führte man die Aufteilung in sechs Verbände ein: „Niemen“ (Memel), „Süd“, „Nord“, „Ost“, „West" und „Stołpec". Polnische Partisanen kontrollierten die Gebiete nordwestlich der Memel.

Im Frühling/Sommer 1943 kam es in der Oblast' Baranoviči zwischen den polnischen und sowjetischen Partisanen zu ersten militärischen Auseinandersetzungen, die mit der Zeit zu einem lokalen polnisch-sowjetischen Krieg eskalierten. Die Ursachen für diesen Konflikt lagen in der Politik der sowjetischen Führung in Moskau begründet. Im Sommer 1941, als die militärische Lage für die Sowjetunion sehr schwierig war, nahm Moskau diplomatische Beziehungen zur polnischen Exilregierung in London auf. Und Stalin ließ aus Lagern und Deportationsorten in Sibirien und Kasachstan Tausende von Polen frei, die dorthin in den Jahren 1939-1941 verschleppt worden waren. Nach Stalingrad ging der siegessichere Stalin in der polnischen Frage wieder in die Offensive. Im April 1943 kündigte Moskau die diplomatischen Beziehungen zur polnischen Exilregierung in London.

$\mathrm{Ab} 1943$ unternahm die sowjetische Führung Versuche, die Heimatarmee als militärischen Faktor in den ehemaligen ostpolnischen Gebieten auszuschalten. Moskau betrachtete das ehemalige Ostpolen als integralen Bestandteil der Sowjetunion. Die Zukunft des künftigen polnischen Staates, der auf den übrigen polnischen Gebieten entstehen sollte, war noch offen. Dieser Staat hatte auf jeden Fall „sowjetfreundlich“, d.h. kommunistisch, zu sein. Die polnische Exilregierung bestand dagegen auf der Wiederherstellung eines unabhängigen polnischen Staates in den Grenzen von 1939. Die Heimatarmee war der bewaffnete Arm der Exilregierung. Hinzu kam, daß die Polen aufgrund ihrer Erfahrungen mit dem sowjetischen Terror der Jahre 1939-41 als besonders sowjetfeindlich galten.

Im Januar 1943 verfaßte Ponomarenko eine Denkschrift zur polnischen Frage, die an Stalin und seine engsten Mitarbeiter gerichtet war. Dort führte er aus, daß es notwendig sei, in Polen einen Partisanenkrieg zu entfachen: Außer dem konkreten militärischen Nutzen, der Entlastung der Rote Armee, werde der Kampf mit den deutschen Besatzern unter den Polen hohe menschliche Verluste verursachen. Auf diese Weise werde es den Polen nicht gelingen, ihre biologischen Kräfte unversehrt zu erhalten. ${ }^{6}$ Auf diesem Wege sollte die künftige Sowjetisierung Polens vorbereitet werden.

3 Anweisung des General Sikorski - Warnung vor dem NKVD, 29. 9. 1942, abgedruckt in: Armia Krajowa w dokumentach 1939-1945, Szczecin 1989, B. II, S. 56 f.

4 Vgl. Bericht der AK Hauptkommandantur, Abteilung IV: „Militärische Lage im Bezirk ,Now’ [Nowogródek, B.M.]“, 19. Juni.1944. AAN, 203/VII-56, Bl. 4.

5 Janusz Prawdzic-Szlaski, Nowogródczyzna w walce 1940-1945, Szczecin 1989, S. 132.

6 Abgedruckt in: Ivan Bilas (Hrsg.): Represivno-karal'na sistema v Ukraïni 1917-1953. Kiew 1994, Bd. 2, S. 360-361. 
$\mathrm{Zu}$ ersten bewaffneten Konflikten zwischen polnischen und sowjetischen Partisanen kam es jedoch nicht aus politischen Gründen, sondern bei der Bekämpfung der Banden. Ab dem Frühjahr 1943 griffen polnische Abteilungen gezielt kriminelle Banden an, welche die Zivilbevölkerung terrorisierten. Nicht selten erwiesen sich die Plünderer aber als sowjetische Partisanen. Im Mai 1943 kam es zu Gesprächen zwischen der AK-Führung im Bezirk Nowogródek und den sowjetischen Partisanen, die auf der sowjetischen Seite die Führung der Brigade "Lenin“ nach Absprache mit „Platon“ führte. Die polnische Seite schlug u.a. vor, gemeinsame Aktion gegen deutsche Besatzer zu führen und entschieden gegen die Banden vorzugehen. Auf Befehl von Ponomarenko wurden diese Gespräche jedoch abgebrochen.?

Ponomarenko sprach sich, wohl nach Absprache mit Stalin, gegen eine Einigung und Waffenbrüderschaft mit den polnischen nichtkommunistischen Partisanen aus und befahl stattdessen ihre Vernichtung. Am 22. Juni 1943 verfaßte Ponomarenko ein Rundschreiben über die militärischen und politischen Aufgaben und Ziele in den westlichen Oblasten Weißrußlands gegenüber der polnischen Untergrundbewegung, das an die Anführer der sowjetischen Untergrundbewegung in diesen Teilen Weißrußlands gerichtet war. ${ }^{8}$ Zwei Tage später wies Ponomarenko in einer Konferenz mit den Anführern der weißrussischen Untergrundbewegung seine Untergebenen an:

[...] unsere Partisanenabteilungen und Parteiorganisationen müssen daran arbeiten, alle entstehenden polnischen Untergrundorganisationen [in den westlichen Oblasten Weißrußlands] aufzudecken und sie dann mit allen möglichen Mitteln den Schlägen der deutschen Besatzer auszusetzen. Die Deutschen werden nicht zögern, Personen zu erschießen, wenn sie erfahren, daß diese Anführer der polnischen Untergrundbewegung oder anderer polnischer Militärorganisationen sind. Hier ist eine Koordinierung notwendig. Wie soll das gemacht werden? Bei der Wahl der Mittel dürft ihr keine Skrupel haben. Dies muß breit angelegt werden und so, daß es glatt vor sich geht. ${ }^{9}$

Am 22. November 1943 schrieb Ponomarenko wiederum an Stalin, daß es notwendig sei, „polnische Abteilungen und Gruppen, die in den westlichen Teilen Weißrußlands operieren und sowjetische Partisanen überfallen, zu vernichten. Alle übrigen polnischen Gruppen, die eine abwartende Haltung bewahren, sollen diskreditiert, entwaffnet, aufgelöst und ihre Anführer liquidiert werden. Diese Angelegenheit ist von großer Bedeutung." 10

Am 26. August $1943 \mathrm{kam}$ es zu einer ersten größeren Aktion gegen im Bezirk Wilna operierende polnische Verbände, als sowjetische Partisanen die AK-Abteilung „Kmicic“ mit 300 Angehörigen liquidierten. Sie luden die Führung der AKAbteilung „Kimicic“ zu Verhandlungen ein und verhafteten sie dabei. Die übrigen

7 Vgl. auch Armia Krajowa na Nowogródczyźnie i Wileńszczyźnie (1942-1944) w świetle dokumentów sowieckich, hrsg. von Zygmunt Boradyn, Andrzej Chmielarz, Henryk Piskunowicz, Warszawa 1997, S. 23-45; Polnische und sowjetische Dokumente dazu veröffentlichte Michał Gnatowski in: Studia Podlaskie, VI, Białystok 1996, S. 231-241.

8 Siehe Dokument Nr. 9.

9 Sitzungsprotokoll des Politbüros des ZK der KP(b)B vom 24. 6. 1943. NARB, f. 4p, op.33a, d. 254, 1.482; abgedruckt auch in: Studia Podlaskie Bd. 5 (1995), S. 233-246, hier S. 243.

10 Notiz des Chefs der ZSdPB, P. Ponomarenko, an Stalin über polnische Versuche, die AK in den Gebieten des westlichen Weißrußlands zu organisieren, abgedruckt in: Konflikty polsko - sowieckie 1942-1944, Warszawa 1993, S. 105. 
Partisanen überraschten sie in ihren Basen und entwaffneten sie. Zum Schluß erschossen die sowjetischen Partisanen den Kommandeur der Abteilung Antoni Burzyński und 80 seiner Männer. Die übrigen seiner Männer gliederten sie zwangsweise in eigene Abteilungen ein bzw. ließen sie ohne Waffen frei. Es konnten jedoch etwa 100 Angehörige der Abteilung „Kimicic“ entkommen. Sie führten danach einen erbitterten Kampf gegen die sowjetischen Partisanenverbände.11

$\mathrm{Zu}$ einer ähnlichen Aktion kam es im Bezirk Baranoviči, als am 1. Dezember 1943 sowjetische Partisanen das AK-Bataillon Stołpec [russ.: Stolbcy] liquidierten. Die Offiziere wurden erschossen bzw. nach Moskau verschleppt, die übrigen Partisanen in die sowjetischen Abteilungen zwangseingegliedert bzw. ohne Waffen freigelassen. Danach eskalierte der polnisch-sowjetische Konflikt in der Oblast' Baranoviči zu einem lokalen polnisch-sowjetischen Partisanenkrieg. Manche AK-Abteilungen, die von den sowjetischen Partisanen besonders bedroht waren, stellten den Kampf gegen die deutschen Besatzer ein und ließen sich sogar von ihnen mit Waffen und Munition versorgen. ${ }^{12}$ Diese Abteilungen konzentrierten sich nun darauf, die sowjetischen Partisanen zu bekämpfen, wobei sie gegen die ausdrücklichen Befehle der Zentrale handelten. ${ }^{13}$

Besonders die Abteilung des Fähnrichs Zdzisław Nurkiewicz [russ. Schreibweise: Nurkevič] setzte den sowjetischen Partisanen zu. Die Führung der Brigade „Žukov“ beschwerte sich im Frühjahr 1944: „Die Bande von Nurkiewicz fügt uns größeren Schaden als die Deutschen zu. Sie bewegt sich straflos in den Rajons Stolpec und Ivenec. Bei plötzlichen Angriffen auf Dörfer tötet sie und nimmt [sowjetische] Partisanen und Personen gefangen, die mit ihnen verbunden sind. "14

Fähnrich Nurkiewicz mit dem Decknamen „Noc“ gehörte mit seinen Reitern dem AK-Bataillon Stołpec an, und entkam der Vernichtung am 1. Dezember 1943, weil er woanders als der Rest des Bataillons stationiert war. Danach nahm er sofort den offenkundig sehr effizienten Kampf gegen die sowjetischen Partisanen auf. Nach sowjetischen Angaben sollen seine Reiter innerhalb von kürzester Zeit von 70 bis 120 sowjetische Partisanen gefangengenommen haben. ${ }^{15}$

Anfang Dezember 1943 geriet auch der Leutnant Fieoktistov in die Hände von Nurkiewicz's Reitern, der Zugführer in der Abteilung Čapajev der Brigade Stalin war. Dabei konfiszierten die Reiter bei Fieoktistov den Befehl zur Liquidierung des AK-Bataillons Stołpce. Fieoktistov ,erwies“ den AK-Partisanen noch einen anderen guten Dienst. Am 1. Dezember 1943, als Fieoktistov mit seinen Männern den Befehl zur Liquidierung der AK-Partisanen ausführte, erschoss er zwei sowjetische

11 Zygmunt Boradyn, Andrzej Chmielarz, Henryk Piskunowicz, Z dziejów Armii Krajowej na Nowogródczyźnie i Wileńszczyźnie (1941-1945). Studia, Warszawa 1997, S. 23-29.

12 Der Kommandeur einer Abteilung meldete am 25. 5. 1944 an den Kommandeur des Bezirks "L“, daß seine Abteilung in der Zeit vom 1. 4.-25. 5. 1944 von den Deutschen u. a. bekommen hat: 110000 Stück Munition, 181 Gewehre, 522 Handgranaten, 12 leichte und 3 schwere Maschienengewehre und andere Ausrüstungsgegenstände wie Karten, Schuhe, Fahrräder, Motorräder, Wäsche. Abschrift: Archiv des Instiuts des Nationalen Gedenkens Katowice, 1/143, Band. 1-4 (Beiakte), ohne Paginierung.

13 Krajewski, Der Bezirk Nowogródek, S. 581; ausführlich Boradyn, Nemen, S. 173 - 187.

14 Schreiben der Führung der Brigade "Žukov" an "Platon" (ohne Datum, wahrscheinlich März 1944): NARB, f. 3500 , op. 4, d. 252, 1. 72.

15 Befehl der Führung der Brigade „Stalin“ vom 2. 12. 1943: NARB, f. 3603, op. 1, d. 31, 1. 85. 
Partisanen der NKVD-Sonderabteilung der Brigade „Čkalov", die polnischer Herkunft waren. Fieoktistov dachte, es handele sich um polnische „Legionäre“, da diese polnische Uniformen trugen, als sie vom Einsatz gegen polnische Partisanen zurückkehrten. Einige Tage später ließ Nurkiewicz Fieoktistov wie auch andere seine Kameraden frei. Nach der Rückkehr in seine Abteilung wurde Fieoktistov vom Kommissar der Abteilung "Čapajev" erschossen, weil er den Liquidierungsbefehl verloren und zuvor die beiden sowjetischen Agenten irrtümlich erschossen hatte. ${ }^{16}$

Nurkiewicz schickte den erbeuteten Liquidierungsbefehl an die AK-Kommandantur des Bezirks Nowogródek, die ihn an die Hauptkommandantur in Warschau weiterleitete, und diese wiederum sandte den Befehl per Funk an die polnische Exilregierung in London. Unter ungeklärten Umständen gelangte der Befehl auch in deutsche Hände, und die Deutschen nutzten den Befehl propagandistisch aus, um die antisowjetischen Gefühle bei den polnischen Partisanen weiter zu schüren. Am 25. April 1944 forderte der Volkskommissar der Staatssicherheit Merkulov Ponomarenko auf, die Angelegenheit aufzuklären. Der Chef des Verbandes Baranoviči „Platon“, an den Ponomarenko die Anfrage weitergeleitet hatte, erklärte in zwei Funktelegrammen vom 2. und 6. Mai 1944, daß Fieoktistov tatsächlich Zugführer in der Abteilung „Čapajev“ gewesen war. Fieoktistov sei jedoch im Januar 1944 erschossen worden, weil er den Polen Dokumente übergeben und im übrigen auch geraubt gehabt habe. Zugleich behauptete „Platon“, daß der Inhalt des Befehls (Liquidierung des AK-Bataillons) von der Gestapo erfunden worden sei. Im selben Sinne berichtete Ponomarenko an Merkulow, wobei er behauptete, Fieoktistov sei ein „polnischer Spion" gewesen und sonst sei für alles andere Gestapo verantwortlich. Zugleich beteuerte Ponomarenko, daß weder der Weißrussische Stab noch der Zentralstab der Partisanenbewegung jemals Befehle zur Liquidierung von polnischen Partisanen erteilt hätten. Erst in den neunziger Jahren wurde ein Exemplar des Befehls zur Liquidierung des AK-Bataillons Stołpce in einem Minsker Archiv gefunden, der bestätigte, daß Nurkiewicz einen authentischen Befehl erbeutet hatte. ${ }^{17}$

Für die Führung des AK-Bezirks Nowogródek kam der Konflikt mit den sowjetischen Partisanen einem Krieg an zwei Fronten gleich: gegen den deutschen und den sowjetischen Feind. Allein von Mai 1943 bis Juli 1944 kam es zwischen den AK-Abteilungen und sowjetischen Partisanen zu mindestens 230 bewaffneten Auseinandersetzungen und Gefechten. ${ }^{18} \mathrm{Nach}$ unvollständigen Angaben waren polnische Partisanen des AK-Bezirkes Nowogródek insgesamt an 459 Aktionen und Kämpfen gegen die Deutschen sowie an 355 gegen die sowjetischen Partisanen beteiligt. ${ }^{19}$

Die sowjetische Seite und die polnischen Kommunisten instrumentalisierten sowohl während, als auch nach dem Krieg die Kontakte der AK-Partisanen im Bezirk Nowogródek und Wilna mit den Deutschen für propagandistische Zwecke, um die $\mathrm{AK}$ als faschistische Kollaborateure und deutsche Agenten zu diskreditieren. Selbstverständlich blendeten sie dabei das Verhalten der sowjetischen Partisanen,

16 Boradyn, Niemen, S. 111, $168 \mathrm{f}$.

17 Ebenda; Zygmunt Boradyn, Rozbrojenie, in: Karta 1995, Nr. 16-17, S. 131.

18 Ausführlich dazu Boradyn, Niemen.

19 Krajewski, Der Bezirk Nowogródek, S. 571. 
ihre Übergriffe gegenüber der Zivilbevölkerung, die gezielten Denunziationen an die Gestapo und auch konkrete Aktionen gegenüber polnischen Partisanen aus. Die westliche Forschung übernahm kritiklos diese Version der Ereignisse. ${ }^{20}$ In den neunziger Jahren erschienen in Polen zahlreiche bisher geheim gehaltene Dokumente und auch Beiträge zum Thema, die die Ereignisse anders, als dies die sowjetische Seite bisher getan hatte, darstellen. Diese Publikationen werden jedoch im Westen wie im Osten weiterhin kaum rezipiert. So überwiegt beispielsweise in Weißrußland weiterhin die sowjetische Sichtweise auf die Heimatarmee. ${ }^{21}$ In Deutschland erschien zuletzt ein Aufsatz von Bernhard Chiari, der sich dieser Thematik widmet. ${ }^{22}$ Chiari berücksichtigt jedoch die neueste Forschung nicht und beschränkt sich auf die deutsch-polnischen Kontakte, ohne auf die Vorgeschichte einzugehen, wie beispielsweise die gescheiterten Verhandlungen der AK mit der sowjetischen Seite, Ponomarenkos Befehle zur Vernichtung des polnischen Untergrundes oder die Übergriffe der sowjetischen Partisanen.

20 So schrieb der Historiker Dov Levin, der selbst Partisan gewesen war, über die Heimatarmee in der Region um Wilno, ohne die Vorgeschichte darzustellen: „The Poles in eastern Lithuania became dangerous and cruel adversaries of Soviet partisans in general, and of the Jews among them in particular." Levin, Fighting Back, S. 182.

21 Vgl. Ivan P. Kren', Der Einsatz der Armia Krajowa auf dem Territorium Weißrußlands aus weißrussischer Sicht. Versuch einer Ortsbestimmung, in: Die polnische Heimatarmee, S. 585 -597; kritisch Sigizmund P. Borodin, Die weißrussische Geschichtsschreibung und Publizistik und die Heimatarmee in den nordöstlichen Gebieten der Republik Polen 1939 bis 1945, in: Ebenda, S. 599-616.

22 Bernhard Chiari, Kriegslist oder Bündnis mit dem Feind? Deutsch-polnische Kontakte 1943/44, in: Die polnische Heimatarmee, S. 497-527. 


\title{
Dokumente
}

\author{
Dokument Nr. 1
}

\section{Anordnung des Bevollmächtigten des ZK der KP(b)B für die Oblast' Baranoviči über die Beziehungen zum polnischen bewaffneten Untergrund (Mai 1943)}

\section{Streng gebeim}

An den Bevollmächtigten des $Z K \operatorname{der} K P(b) B$

für das Vereinigte Rajonzentrum Ivenec, Oblast' Baranoviči, Gen. Dubov.

An die Bevollmächtigten des $Z K$ der $K P(b) B$

für die Vereinigten Rajonzentren Lida und Š́učino

Laut uns vorliegenden Angaben operiert im Raum Lugomoviči eine bis zu 50 Mann starke Gruppe von bewaffneten Polen gegen die Partisanen (sie geht in kleinen Gruppen vor). Infolge des bewaffneten Kampfes der uns feindlich gesinnten Polen wurde im Dorf Zabylinka ein Partisan getötet und ein weiterer verwundet.

Beim Dorf Traby töteten die Polen mehrere Zivilpersonen aus der örtlichen Bevölkerung, weil sie den Partisanen helfen. Bekannt ist, daß zu diesen Gruppen der Sowjetmacht feindlich gegenüberstehende, notorische Faschisten gehören.

So operiert im Dorf Lugomoviči eine 5 Mann starke polnische Gruppe gegen die Partisanen; zu ihr gehören: der ehemalige Polizeikommandant Edvard Kulpekša, der ehemalige Polizist Koper u.a.

Sie halten sich in den Dörfern Kačevo und Korišinjata versteckt.

Alle polnischen Gruppen sind gut bewaffnet, haben u. a. Maschinenwaffen.

Außerdem wurde festgestellt, daß die Polen ihre bewaffneten Untergrundorganisationen systematisch ausbilden. Im Dorf Griniči, Rajon Stolbcy, steht Leutnant Milaševskij und in der Stadt Stolbcy Hauptmann Rakovskij, zugleich Leiter der polnischen Kreisorganisation, an ihrer Spitze. Insgesamt werden im Rajon Ivenec nach unvollständigen Angaben bis zu 700 ausgebildete Polen gezählt, die der Organisation angehören.

Ich schlage vor, eine spezielle Operation zur Vernichtung der bewaffneten Polengruppen, die im Raum Lugomoviči operieren, vorzubereiten.

Die Verräter Edvard Kulpekša und Koper müssen lebend gefaßt werden.

$\mathrm{Zu}$ diesem $\mathrm{Z}$ weck haben Sie speziell Leute aus den Partisanenabteilungen auszuwählen, die diese Aufgabe exakt erledigen und die Konspiration bei unseren Aktionen gegen die polnischen Organisationen streng wahren würden. Außerdem gilt es, die Massenagitation unter der polnischen Bevölkerung entscheidend zu verstärken und dazu die verräterische Tätigkeit der polnischen Untergrundorganisationen sowie die Regierung Sikorski zu entlarven. Unsere Propaganda muß der Bevölkerung 
klar machen, daß die gegen die Partisanen kämpfenden Polen Agenten der Deutschen und Verräter am polnischen Volk sind.

Bevollmächtigter des ZK der KP(b)B

Sekretär des Oblastkomitees Baranoviči der $\mathrm{KP}(\mathrm{b}) \mathrm{B}$

\author{
(PLATON)
}

F. 1329, op. 1, d. 29, 1. 29.

\title{
Dokument Nr. 2
}

\section{Schreiben der Führung der Armija Krajowa des Bezirks Nowogródek an die Leitung der Lenin-Partisanenbrigade vom 14. Juni 1943}

Hauptstab

der polnischen Partisanen

Kopie

Nr. 344/43

14. Juni 1943

\section{An den Stab der sowjetischen Lenin-Partisanenbrigade}

Nachstehend Antworten auf Punkte die in Ihrem Protokoll angesprochen wurden, das wir bei der Begegnung mit meinem Delegierten am 8. Juni 1943 erhalten haben.

$\mathrm{Zu}$ P. 1. Andere militärische Organisationen als polnische gibt es weder auf dem Territorium dieses Rajons noch auf dem Territorium von ganz Polen, und nur ein Delegierter des Hauptstabes der polnischen Partisanen „Vostok“ hat das Recht, Verhandlungen zu führen; was die sowjetische Seite betrifft, so wird der Hauptstab der polnischen Partisanen „Vostok" nur mit Delegierten der Militärabteilungen der sowjetischen Partisanen und nur durch Vermittlung der Lenin-Brigade verhandeln.

$\mathrm{Zu}$ P. 2. Der Stab der polnischen Partisanen "Vostok“ beschränkt sich darauf, Kontakte vorläufig nur zur Lenin-Brigade der sowjetischen Partisanen herzustellen. Nach Maßgabe der Erweiterung der gemeinsamen Arbeit werden sich diese Kontakte mit der Zeit unter Vermittlung der Lenin-Brigade auch auf andere Abteilungen erstrecken. Zur weiteren Ausdehnung der Kontakte muß sich der Stab der Lenin-Brigade mit den benachbarten sowjetischen Brigaden in Verbindung setzen, um zur besserer Verbindung Stützpunkte zu schaffen. Ein Delegierter des polnischen Hauptstabes wird die technische Lösung dieser Frage (Parole, Kennzeichen usw.) präzisieren.

$\mathrm{Zu}$ P. 3. Delegierte des polnischen Stabes werden durchaus vertrauenswürdige und jedesmal mit entsprechenden Parolen oder schriftlichen Bescheinigungen ausgestattete Personen sein.

$\mathrm{Zu}$ P. 4. Der polnische Stab ist bereit, Angaben über gegen die Partisanen geplante Razzien - ihren Umfang, ihre genaue Richtung und Stärke - zu liefern. Bei kleinen Angriffen, wenn kleine Kräfte schnell in eine Richtung entsandt werden, wird eine Mitteilung wegen Zeitmangels schwer fallen, es wären dann verspätete Nachrichten.

$\mathrm{Zu}$ P. 5. Der polnische Stab findet sich bereit, Angaben über die Positionen der deutschen Truppen zu liefern. 
Zu P. 6. Detaillierte Veränderungen sollen nach endgültigem Beschluß über gemeinsame Operationen mitgeteilt werden.

$\mathrm{Zu}$ P. 7. Von einem Beschuß der sowjetischen Partisanen im Raum der Dörfer Jachonty, Neteča und Cacki kann keine Rede sein. Die Operationen unserer Abteilungen richteten sich gegen die örtlichen Banditen, und der beste Beweis dafür waren die im Dorf Jachonty im Lagerraum eines gewissen Ščotka gefundenen geraubten Sachen: Damenwäsche und -kleidung, Schuhe, eine Schaffelljacke und zwei Filzumhänge, 2 Stück Leinwand, 3 Paar Herrenwäsche und anderer Kram. Einen Teil dieser Sachen erkannte der Sohn des getöteten Kämpfers unserer Abteilung Klivec wieder. Fakt ist dagegen, daß auf jenem Territorium unsere Landarbeiterin Olja Voznikova aus Neteča bestialisch ermordet, nämlich in ein brennendes Haus geworfen wurde. Sowjetische Partisanen tun doch sonst nicht so etwas mit der wehrlosen Bevölkerung. Der Delegierte des polnischen Stabes könnte noch mehr solcher Fälle aufzählen.

Miščuk ist ein mittlerer Kommandeur und handelt auf Befehl der polnischen Leitung. Was den Mord am Hausbesitzer in Tobol angeht, so wird der Delegierte des polnischen Stabes das klären, auf jeden Fall war das ein schädliches Element, er wollte eine polnische Partisanin den Deutschen preisgeben.

Der Stab der polnischen Partisanen fordert, daß die sowjetischen Abteilungen aus den Amtsbezirken Belickaja und Dukodovskaja abgezogen werden und dieses Territorium künftig meiden, damit es bei der Tötung von Banditen durch polnische Abteilungen nicht zu Mißverständnissen kommt.

Die auf diesem Territorium untergebrachten sowjetischen Abteilungen unternehmen keine Diversionsakte gegen die Deutschen und unterdrücken lediglich die polnische Bevölkerung, wodurch sie diese gegen die Sowjetmacht aufbringen.

$\mathrm{Zu}$ P. 8. Gegenseitige Hilfe bei den Operationen wird Gegenstand einer engen gemeinsamen Arbeit der Stäbe sein.

$\mathrm{Zu}$ P. 9. Gegenseitiges Vertrauen muß auf der Respektierung der polnischen Forderungen und Interessen beruhen.

Der polnische Stab behält sich das Recht vor, seine Soldaten in Übereinstimmung mit dem eigenen politischen Programm zu erziehen. Der polnische Stab wird sich mit keinerlei Versuchen der kommunistischen Propaganda unter der örtlichen Bevölkerung und unseren Soldaten abfinden, was auch mit dem zwischen General Sikorski und Stalin abgeschlossenen Vertrag von 1941 übereinstimmt. Der polnische Stab vertritt die Auffassung, daß angesichts des gemeinsamen Feindes die Kampfgemeinschaft zu einer aufrichtigen Waffenbrüderschaft der Soldaten heranwächst.

$\mathrm{Zu}$ P. 10. Aus Sicherheitsgründen (Abhören) finden wir das überflüssig. Die Funkverbindung kann während der Kampfhandlungen hergestellt werden.

$\mathrm{Zu}$ P. 11. Die Hilfe kann sich auf folgende Bereiche erstrecken: Führer im Rajon, Parolen, Aufklärung. Für ihre Verpflegung müssen die sowjetischen Abteilungen selbst sorgen, ohne hierbei der örtlichen Bevölkerung Schaden zuzufügen.

$\mathrm{Zu}$ P. 12. Der nächste Kontakt erfolgt nach Abschluß der Verhandlungen mit der Lenin-Brigade.

Zu P. 13. Siehe P. 12.

$\mathrm{Zu}$ P. 14. Mit der Frist von einer Woche ist der polnische Stab einverstanden. AuBerdem verlangt der polnische Stab durch die sowjetische Seite unterzeichnete Kopien der Protokolle zu den Verhandlungen mit dem polnischen Delegierten vom 
8. Juni 1943 wie auch eine schriftliche Antwort auf die im genannten Protokoll dargelegten Forderungen des polnischen Stabes.

Kommandeur der polnischen Partisanen „Vostok“ (Jasica)

Kopie und Übersetzung aus dem Polnischen beglaubigt:

Stabschef der Lenin-Brigade

Oberleutnant

F. 3500, op. 4, d. 251, Il. 32, 32 Rückseite.

\section{Dokument Nr. 3}

\section{Beschluß der Leitung der Lenin-Brigade vom 15. Juni 1943}

\section{Beschlu $\beta$}

Der Leitung der Lenin-Brigade der sowjetischen Partisanen

Nach Prüfung der Forderungen des Delegierten des Hauptstabes der polnischen Partisanen „Vostok“, die im Protokoll vom 8. Juni 1943 gestellt und registriert wurden, hat die Leitung der Lenin-Brigade der sowjetischen Partisanen am 15. Juni 1943

\section{BESCHLOSSEN:}

Mit Rücksicht auf die gemeinsamen Interessen beider Seiten im Kampf gegen den gemeinsamen Feind, die deutschen Okkupanten, und angesichts der allgemeinen Versklavung, der Vernichtung der gesamten nationalen Kultur des belorussischen, des polnischen und der anderen slawischen Völker akzeptieren wir folgende vom Delegierten des Hauptstabes der polnischen Partisanen „Vostok“ gestellten Punkte:

1. Allgemeine Abstimmung der Partisanenaktionen gegen den gemeinsamen Feind, die deutschen Okkupanten, die in einzelnen Fällen die Form gemeinsamer Kampfoperationen annimmt.

2. Nach Möglichkeit vorzunehmender Austausch von Waffen und sonstigen Materialien.

3. Enge Verbindung und Freundschaft.

4. Vertrauen und Hilfe auf beiden Seiten. Begegnungen nur in sachlichen dienstlichen Fragen.

5. Kontakte und Begegnungen nur über Delegierte der Stäbe an im Voraus bestimmten Orten. Die jeweils nächste Begegnung wird von beiden Seiten bei der laufenden Begegnung, jede außerordentliche Begegnung über Melder festgelegt.

6. Die Entsendung der Korrespondenz jeder Seite erfolgt nur in einem mit einem Siegellackstempel verschlossenen Umschlag, in einzelnen Fällen ist die Korrespondenz zu chiffrieren, wozu eine gemeinsame Chiffre festzulegen ist.

7. Für Begegnungen der von den Stäben bevollmächtigten Personen ist eine $\mathrm{Pa}$ role zu vereinbaren.

8. Wir sind kategorisch gegen die Unterstellung unter den Stab der polnischen Partisanen „Vostok“, weil wir unter der Führung unseres Gesamtzentrums des Kampfes gegen den Faschismus stehen. (Der von der Sowjetregierung mit General 
Sikorski abgeschlossene Vertrag bezieht sich in keiner Weise auf die Zeit, wo im Lande die deutschen Okkupanten schalten und walten.)

9. Der Wirkungsbereich der Lenin-Brigade, ebenso wie der aller übrigen Brigaden und Abteilungen der sowjetischen Partisanen, ist das ganze von den Deutschen okkupierte sowjetische Territorium.

10. Was die Übergabe eines Teils der Lipičany-Pušča als Basis für die polnischen Partisanen betrifft, so erfolgt hierüber später, nach Klärung dieser Frage in übergeordneten Führungsorganen, Mitteilung.

11. Um der besseren Manövrierfähigkeit der sowjetischen Partisanen bei der Durchführung überraschender Schläge gegen den Feind und seiner Verbindungswege willen, können wir die freie Bewegung der Kampfabteilungen der sowjetischen Partisanen nicht behindern. Zugleich versichern wir, daß die sowjetischen Partisanen nach wie vor unversöhnlich gegen Banden, die nur auf Terror, Plünderungen und persönliche Bereicherung aus sind, kämpfen und über das Auftauchen derartiger Banden den Bevollmächtigten des Hauptstabes der polnischen Partisanen "Vostok" informieren werden, damit Maßnahmen zur Vernichtung dieser Banden getroffen werden können.

12. Das Brigadekommando übernimmt es im weiteren, je nach der Nützlichkeit der Verbindungsaufnahme, die Bevollmächtigten des Hauptstabes der polnischen Partisanen „Vostok" mit Brigaden und einzelnen Abteilungen der sowjetischen Partisanen in Verbindung zu bringen. Diese Verbindung muß den gemeinsamen Interessen beider Seiten dienen.

13. Beim Aufkommen von Banden, beim Auftreten von Banditentum und bei der Feststellung solcher Erscheinungen durch eine der Seiten ist ihre Vernichtung mit Wissen beider Seiten anzustreben. In allen Fällen ist die andere Seite in Kenntnis zu setzen, um zu vermeiden, daß ehrlich kämpfende sowjetische und polnische Partisanen vernichtet werden.

14. Wir werden Landgüter nur niederbrennen, wenn es notwendig ist (im Gefecht, wenn dort deutsche Garnisonen untergebracht sind usw.).

15. Für Entsendungen zum Erwerb von Verpflegung in die Dörfer sind bewährte, ehrliche, taktvolle Partisanen auszuwählen. In jedem einzelnen Fall nicht taktvollen Verhaltens seitens der Partisanen, gleich welcher Nationalität, sind sie streng zu bestrafen.

16. Wie geklärt wurde, geschah der Mord an der Geliebten Miščuks in Nesviž nach mehreren von Miščuk begangenen Meuchelmorden an Partisanen.

17. Der Eisenbahner Stankevič wurde bei Lida beim Beschuß eines deutschen Kraftfahrzeuges getötet (niemand konnte wissen, daß im Wagen der Deutschen anständige und nützliche Menschen mitfahren würden).

Wir bekräftigen unsererseits die von uns erhobenen Forderungen, die im Protokoll vom 8.6. 43 fixiert sind.

Zugleich verlangen wir, daß Ihre Organisation den Kampf gegen die sowjetischen Partisanen einstellt und daß der Mord an unseren 16 Partisanen am 11. Juni 1943 in den Gehöften des Dorfes Bojary-Smoločanskie untersucht wird. Die Anstifter dieses niederträchtigen Verbrechens sind festzuhalten und in unserer Anwesenheit zu bestrafen.

Im weiteren werden wir jeden von Ihrer Seite begangenen Mord an unseren Anhängern und Partisanen als Erfüllung eines Auftrags der deutschen Okkupationsbe- 
hörden zur Vernichtung der sowjetischen Partisanen einstufen und uns nach dem ersten Wiederholungsfall eines solchen Mordes als berechtigt betrachten, über die Vernichtung dieser Banden und ihrer Anführer frei zu entscheiden.

Der späteste Termin für die Untersuchung und Bestrafung für den bestialischen Mord an 16 Partisanen ist der 23. Juni 1943.

Kommandeur der sowjetischen

Lenin-Partisanenbrigade

Hauptmann

(Siničkin)

F. 3500, op. 4, d. 251, 11. 33-35.

\section{Dokument Nr. 4}

Kopie des Funkspruches des Chefs des Zentralstabes der Partisanenbewegung vom 16. Juni 1943 über die Einstellung zu den polnischen bewaffneten

Formationen

An „Platon“

Übermittle Beziehung zu polnischen Formationen. Bitte um ausführliche Mitteilungen. Bemühen Sie sich jetzt, genau zu untersuchen und mitzuteilen: Familiennamen der Leiter und ihre Parteien, ihre Zugehörigkeit, Stärke, ihr Führungssystem und ihren Ausbildungsstand. Bringen Sie in Erfahrung, wer hinter ihnen steht. Berücksichtigen Sie, daß es in den polnischen nationalistischen Organisationen viele deutsche Spione gibt. Nicht ausgeschlossen, daß mit Ihnen eingeschleuste Leute verhandeln. Hüten sie sich vor Provokationen. Über alles neuerhaltene Material unverzüglich funken.

Ponomarenko.

16. 6. 1943, Nr. 278.

F. 1329 , op. 1, d. $80,1.8$.

\section{Dokument Nr. 5}

Schreiben der Führung des AK-Bezirks Nowogródek an die Leitung der LeninBrigade vom 22. Juni 1943

Leitung

der polnischen Partisanen

„Vostok“

Nr. $345 / 43$

22. 6.43
Kopie.

Übers. aus dem Polnischen.

Stab der Lenin-Brigade

der sowjetischen Partisanen

Nach einer Diskussion über den Beschluß der Leitung der sowjetischen Partisanen vom 17.6. 43 gelangte der Stab der polnischen Partisanen "Vostok" bei seiner Sitzung vom 20. 6. $43 \mathrm{zu}$ Schlüssen, die er als seinen unabänderlichen Beschluß folgenden Inhalts zur Kenntnis bringt: 
Bis jetzt hat der Stab der polnischen Partisanen durch seine Loyalität den auf dem polnischen Territorium befindlichen Abteilungen der sowjetischen Partisanen gegenüber nur den Wunsch bewiesen, zusammenzuarbeiten und herzliche Beziehungen zu diesen Abteilungen herzustellen, wohl wissend, daß nur eine aufrichtige, auf gegenseitigem Vertrauen beruhende gemeinsame operative Arbeit im Kampf gegen den gemeinsamen Erzfeind der Slawen gute Resultate bringt. Diese gemeinsame Arbeit faßt der Stab der polnischen Partisanen nur als ein Verhältnis von gleich zu gleich auf, ausgehend von dem abgeschlossenen polnisch-sowjetischen Vertrag und der Äußerung von Marschall Stalin über die Bedürfnisse eines großen Polen als souveränes Nachbarland der UdSSR.

Wegen der Unklarheit einiger Punkte in dem Beschluß der sowjetischen Partisanen vom 1. 6. 43 beschließt der Stab der polnischen Partisanen, sie noch einmal kritisch unter die Lupe zu nehmen, weil er sie nicht akzeptieren kann, da sie zum einen nicht den Lebensinteressen der örtlichen Bevölkerung und der Kampfabteilungen der polnischen Gruppen entsprechen, zum anderen der Souveränität der polnischen Abteilungen Abbruch tun.

Darlegung nach Punkten:

Zu P. 8. Der Stab der polnischen Partisanen ist der Ansicht, daß die Unterstellungsverweigerung der um der gleichen Idee und des gleichen Zieles willen wirkenden Gruppen, besonders bei Kampfhandlungen, leicht zur Schwächung und zu Störungen unter den verbündeten Gruppen führen und sie zu einer mühelosen Vernichtung durch den dank seiner Einheit starken Gegner verurteilen kann, der entschlossen ist, nicht nur die Partisanenabteilungen, sondern auch die diesen Abteilungen helfende örtliche Bevölkerung völlig zu liquidieren. Deshalb vertritt der polnische Stab die Auffassung, daß bei der Durchführung einer gemeinsamen Kampfaktion die Leitung nur in den Händen des Stabes der polnischen Partisanen liegen kann, da er über die Bedingungen und die örtliche Situation gut orientiert ist und außerdem über eine eigene Aufklärung verfügt.

$\mathrm{Zu}$ P. 9. Von der Leitung der sowjetischen Partisanen fordern wir kategorisch, die Bestimmung der Grenzen der Kampfhandlungen uns zu überlassen, weil die Grenze unseres Einflusses und unserer freien Handlungen durch die polnisch-sowjetische Linie vor dem 1.9. 1939 festgelegt wurde. Aus diesem Grund ist jegliche Operation von Gruppen auf diesem Territorium mit uns abzustimmen. Wir unsererseits verpflichten uns, diese Grenze nicht in östlicher Richtung durch unsere Operationen zu verletzen. Deshalb fordern wir, uns jene in den Abteilungen der sowjetischen Partisanen befindlichen Polen zu übergeben, die von diesem Territorium stammen.

Zu P. 10. In der von uns erhobenen Frage, der Überlassung der Lipičanskaja Pušča an uns, bleibt unsere Forderung unverändert, und das ist nicht nur dadurch begründet, daß diese Pušča innerhalb der Grenzen Polens liegt, sondern auch strategisch für unsere Abteilungen wichtig ist. Falls Sie auch weiter einer klaren Antwort auf unsere Forderungen ausweichen, werden wir, obzwar wir ein Blutvergießen zwischen Brüdern um jeden Preis vermeiden möchten, bei Ihrer Weigerung oder der Hinauszögerung der Antwort zu entsprechenden Schritten gezwungen sein.

$\mathrm{Zu}$ P. 11. Wir sind zwar mit der freien Bewegung der sowjetischen Partisanenabteilungen auf dem Territorium, das nicht nur von unseren Abteilungen besetzt ist, [...] und mit abgestimmten Kampfhandlungen in den vorgemerkten Sektoren ein- 
verstanden, aber unabhängig davon, welche Position die Leitung der sowjetischen Partisanen uns gegenüber später einnehmen wird, erklären wir klipp und klar, daß wir jene Abteilungen vernichten werden, die versuchen sollten, die örtliche Bevölkerung auszuplündern oder ohne Grund an jemandem Rache zu nehmen, wie das in Neteča geschah. Wir betrachten uns als Verteidiger der örtlichen Bevölkerung; als diese erfüllen wir gewissenhaft unsere Pflicht, den gegen die Okkupanten kämpfenden Abteilungen sowie den polnischen Soldaten zu helfen, die das Vermögen und das Leben unserer Bürger schützen, wie das in dem zwischen den Regierungen der UdSSR und Polens abgeschlossenen Vertrag festgeschrieben ist.

Wir werden den Schutz der Verbrecherbanden - und eine solche war zweifellos die von uns zerstörte Formation - als eine vorsätzliche Diversion betrachten, die in unserem Hinterland unternommen wird zur Schwächung des Vertrauens, das die örtliche Bevölkerung zu uns hat, und zur Beleidigung der gesamten Partisanenbewegung, wie das in weiten von der Partisanenbewegung eingenommenen Räumen vorkommt, was zweifelsohne den Okkupanten in die Hand spielt. Beide Seiten müssen untereinander abgestimmt nicht nur solche Banden vernichten, sondern auch ähnliche Vorkommnisse in den eigenen Gruppen bestrafen. Die ganze Abteilung trägt die Verantwortung für den Einzelnen.

Zur Bestätigung unserer Darlegungen fügen wir ein authentisches Protokoll bei.

$\mathrm{Zu}$ P. 16. Wir halten Ihre Erklärung über den Mord und die Verbrennung des Gehöftes in Neteča für herzlos und für einen Wunsch, sich der Verantwortung zu entziehen; die Beschuldigung, die Getötete habe mit dem Bürger Miščuk ein intimes Verhältnis gehabt, ist beleidigend für eine ehrliche und für die Zukunft arbeitende Polin.

Die Rache, die Miščuk später durch die Vernichtung der Banditenformation nahm, und die Zettel, die er auf den Leichen hinterließ, billigen wir zwar nicht, verstehen jedoch sehr wohl die Motive seines Racheaktes, denn er war durch die Sowjetmacht dreimal angeklagt und um seinen Arbeitsplatz gebracht und seine zur Sowjetmacht loyal stehende Familie deportiert worden, und alles nur weil er Pole war. Heute können wir dem Beleidigten nicht eine so weit gehende Erniedrigung zumuten, weil das entgegengesetzte Resultate zeitigen kann.

Genauso unwahr ist, es sei unmöglich gewesen, im getöteten polnischen Eisenbahner Stankevič einen polnischen Bürger zu erkennen: Der Genannte war von den Deutschen schon durch das Tragen einer speziellen Armbinde am linken Arm gekennzeichnet worden, und die tragen nur Arbeiter, nur polnische Bürger.

Zugleich wurde, wie zum Spott, einem deutschen Beamten die Flucht ermöglicht. Schon das ist höchst aufschlußreich, darüber hinaus wurde die Leiche eines schuldlosen Menschen verunstaltet.

Was die anderen von der Leitung der sowjetischen Partisanen im Beschluß vom 17.6.43 formulierten Punkte angeht, so halten wir sie alles in allem für begründet und nehmen sie vorbehaltlos an.

Wir wollen der Papierdiskussion, die gewöhnlich fruchtlos ausgeht und vom gesetzten Ziel abweicht, ein Ende setzen. Angesichts des Versuches, unsere klare Lage in falschem Licht darzustellen, des ungerechten Vorwurfes, wir hätten in Bojary angeblich eine Partisanenabteilung vernichtet, der persönlichen Beleidigung, ja Beschuldigung, den Deutschen Beistand zu leisten, sowie der gegen uns ausgestoßenen Drohungen wegen künftiger selbständiger Handlungen unserer Abteilungen unter 
der polnischen Bevölkerung sei folgendes erklärt. Nicht um unsere Handlungen, die wir für richtig halten, zu begründen, sondern um ein wirkliches Bild zu vermitteln und der Wahrheit zu ihrem Recht zu verhelfen, fügen wir das oben erwähnte Protokoll bei, aus dem klar hervorgeht, daß die vernichtete Formation in ihrer Mehrheit aus Plünderern bestand, die bei gemeinem Raub erwischt wurden. Nach unseren Begriffen konnte es sich dabei auf keinen Fall um eine reguläre Abteilung der sowjetischen Partisanen handeln, die gemäß der verpflichtenden Ehre der Kämpfer der Roten Armee vorgehen.

Aus diesem Grund beabsichtigen wir nicht, den Kommandeur und die Abteilung zu bestrafen, und halten Ihre Forderung für eine Einmischung in die internen Angelegenheiten unserer Abteilungen.

Zugleich teilen wir der Leitung der sowjetischen Partisanenabteilungen mit, daß wir jeden Fall einer bewaffneten Aktion gegen die örtliche Bevölkerung, der Agitation gegen uns oder einer Kollision mit unseren Kampfabteilungen als Kriegserklärung auffassen und dementsprechend handeln werden. Unsere Erklärung ist nicht als Drohung zu verstehen, sondern als Behauptung einer festen Position gegenüber den Ansprüchen und unbegründeten Vorwürfen sowie dem fehlenden Willen der Leitung der sowjetischen Partisanenabteilungen, die Konturen gemeinsamer Operationen mit uns klar zu umreißen.

Unsere Erklärung als Ganzes zusammenfassend, können wir nicht umhin, auf die Ergebnisse des Zusammenwirkens bei unseren bis heute laufenden Verhandlungen mit der Leitung der sowjetischen Partisanenabteilungen einzugehen, und wir kommen zu dem Schluß, daß wir unsererseits sehr viel zugestehen, nämlich:

1. Die Möglichkeit für die sowjetischen Partisanenabteilungen, sich auf diesem Territorium aufzuhalten, was auch die Möglichkeit der Verpflegung und der Unterbringung dieser Abteilungen einschließt.

2. Die Möglichkeit, der Leitung der sowjetischen Partisanenabteilungen Nachrichten - sowohl solche über die jeweilige Situation als auch Aufklärungsangaben zu übermitteln.

3. Die Möglichkeit des Zusammenwirkens bei Kampfoperationen, wobei wir nicht nur das ländliche, sondern auch das städtische Territorium beherrschen.

Dabei hören wir von der Leitung der sowjetischen Partisanen nur nichtssagende Versprechungen, ja Drohungen, die auf keinen Fall als Anerkennung für unsere bisherige Gewissenhaftigkeit und das treue, herzliche Streben nach gemeinsamem Vorgehen verstanden werden können.

Wir wünschen einen günstigen Abschluß dieser Konferenz und setzen den Termin für den endgültigen Beschluß der Leitung der sowjetischen Partisanen - der Lenin-Brigade - fest: drei Tage ab Empfang des vorliegenden Schreibens.

Falls bis dahin keine Antwort eingeht, werden wir das als den Abbruch unserer bisherigen Beziehungen ansehen und behalten uns die Entscheidung über freie Handlungen vor.

Kommandeur der polnischen Partisanen „Vostok“

Jasica.

\section{Anbang Nr. 1}

Protokoll der Untersuchung, angefertigt am 11. Juni 1943 auf Befehl des Bürgers Jasica, Kommandeur der polnischen Partisanen „Vostok“, durch eine Sonderkommission, bestehend aus: dem 
Bürger Vichor als Vertreter der Leitung der polnischen Partisanen „Vostok“, und den Bürgern Iglickij, Koljarcčik und Danis als Mitglieder der Sonderaufklärung der Leitung der polnischen Partisanen, über das Verbrechen und die verbrecherischen Handlungen der Plündererbande, die in der Umgebung von Bojary durch einen Straftrupp der polnischen Partisanen liquidiert wurde.

Nach einer sorgfältigen Untersuchung kommt die Sonderkommission zu folgendem Schluß:

Um 23.45 Uhr am 10. Juni 1943 führte eine 20 Mann starke Bande, die sich als sowjetische Partisanen ausgab, einen räuberischen Angriff und plünderte folgende Bürger, denen sie folgende Sachen wegnahm:

1. Cybruk - mehrere Herrenjacken, Herren- und Damenwäsche.

2. Radzivon - den ganzen Inhalt eines Schrankes mit Wäsche und Kleidung, ein Wandspiegel wurde zerstört, alles im Hause kaputt gemacht. Außerdem eine Nähmaschine geraubt.

3. Narčuk - Herrenkleidung, Wäsche, ihm wurden die Schuhe von den Füßen gerissen, ferner Schinken und Würste gestohlen.

4. Novak - eine Schreibmaschine, ein Mikroskop, die ganze Kleidung, selbst Damenkleidungsstücke.

5. Bortnik - die ganze Herren- und Damenkleidung, Damen- und Herrenwäsche, Tisch- und Bettwäsche.

6. Fedorovič - den letzten Anzug.

Es gibt noch mehr Betroffene.

Die Abteilung der Plünderer sah nicht wie eine reguläre Partisanenabteilung aus, weil jeder von ihnen auf eigene Faust vorging, ohne auf jemanden zu hören. Auf die Frage, wozu sie die Damenwäsche stahlen, antworteten sie: „Halts Maul, wir haben auch Partisaninnen." Außerdem beschimpften sie die örtliche Bevölkerung unflätig, nannten die Leute sogar "polnisches Pack“.

Unter den Plünderern wurden mehrere Personen wiedererkannt, die früher mehrere Terrorakte aus persönlichen Motiven verübt hatten, weil sie in dieser Gegend oder in der Nähe auch unter der Sowjetmacht lebten.

Identifiziert wurden: Šmukst, Lojko, Drob, [...] und mehrere andere. In der Bande gab es eine Frau.

Nachdem die Plünderer mit der Beute weggezogen waren, schickte ein Aufklärungstrupp zwei Leute vor, die den Banditen auf dem Fuß folgten, und, als diese in einem Versteck das Geraubte verteilten, die nächste Strafabteilung der polnischen Partisanen benachrichtigten, die alle Plünderer vernichtete.

Hiermit ist das Protokoll abgeschlossen und unterschrieben.

Kommissionsvorsitzender Vichor

Mitglieder: Iglickij, Kolarčyk, Danis.

Geprüft: Kommandeur der polnischen Partisanen „Vostok“ .... . Jasica

Kopie aus dem Polnischen richtig übersetzt.

Stabschef der Lenin-Brigade

Oberleutnant

F. 3500, op. 4, d. 251, 11. 36-37. 


\section{Dokument Nr. 6}

Schreiben des Bevollmächtigten des ZK der KP(b)B und des Zentralstabes der Partisanenbewegung für die Oblast' Baranoviči vom 29. Juni 1943 über die Einstellung der Verhandlungen mit der Leitung der Armija Krajowa im Kreis Novogrudok

\section{Streng gebeim}

An Gen. Šupenja

Nach uns vorliegenden Angaben sind die Leute, die mit Euch angeblich als polnische Partisanen verhandeln, nichts anderes als deutsche Provokateure.

Alles, was Ihr mit den Verbindungen vorhabt, ist nicht nötig. Ihr dürft euch mit ihnen nicht in Verbindung setzen, wir brauchen auch ihre Aufklärungsangaben nicht, wir müssen unsere eigene und sonstige Aufklärung durchführen. Zudem hast Du mir bei Deinen Verhandlungen mit der polnischen Leitung nichts über ihre Stärke, Bewaffnung, Unterbringung mitgeteilt, vielmehr seid Ihr darangegangen, irgendwelche diplomatischen Protokolle eines Abkommens zu schreiben, die keiner braucht. Mir ist bekannt, daß die Leute, mit denen Ihr verhandelt, vorläufig zahlenmäßig nicht sehr stark sind, es handelt sich um einige wenige kleine Gruppen von je 50-60 Mann.

Sie verüben Provokationen gegen unsere Partisanen und versetzen ihnen Schläge, wo sie nur können. Das sind nicht polnische Partisanengruppen, sondern von Deutschen gebildete Gruppen.

Aus allen Materialien, die Du mir geschickt hast, ist ersichtlich, daß mit Euch Deutsche verhandeln, die sich für polnische Partisanen ausgeben, und daß die Gruppen, die unsere Partisanen schlagen, deutsch sind. Zu dieser Frage drucken wir ein Flugblatt. Diese aus Polen bestehenden deutschen Gruppen sind zu vernichten. Verhandlungen einstellen. Sie nicht in die Pušča eindringen lassen.

Die Dislozierung dieser Gruppen feststellen und Maßnahmen zu ihrer Vernichtung treffen. Über die Frage der Beziehung zu polnischen Organisationen sende ich einen Funkspruch des Gen. Ponomarenko, davon müßt Ihr Euch leiten lassen. Es ist überall und in jedem Ort zu erläutern, daß Leute, die die Partisanen überfallen, nicht polnische Partisanen, sondern deutsche Agenten sind.

Warte auf ausführliche Nachrichten.

29.6. 1943

Černyšev

F. 1329, op. 1, d. 80, 11. 10.

\section{Dokument Nr. 7}

Schreiben der Leitung der Lenin-Brigade an die Leitung der Armija Krajowa des Bezirks Nowogródek vom 30. Juni 1943

30. Juni 1943.

Nr. $22 / 43$

Stab der polnischen Partisanen "Vostok“

Nach Prüfung Ihres Beschlusses Nr. 345/43 vom 26. 06. 43 über Ihre Entscheidung vom 17.06. 43 betr. Ihre Ablehnung von fünf Punkten faßt der Stab der Le- 
nin-Brigade der sowjetischen Partisanen in der Sitzung vom 29.06. 43 folgenden endgültigen Beschluß:

1. Sie berufen sich auf eine Äußerung von Marschall Gen. STALIN „Über die Bedürfnisse Großpolens als souveränes Nachbarland der UdSSR“. Die Politik unserer Sowjetregierung und des Gen. STALIN „Über die Wiederherstellung eines starken und unabhängigen Polen" ist unsere Politik, und wir werden sie unentwegt realisieren. Wir werden alle unsere Kräfte einsetzen, um die Zerschlagung unseres gemeinsamen Feindes zu beschleunigen und die Freundschaft zwischen dem Sowjetvolk und dem polnischen Volk, beiden souveränen befreundeten Staaten zu festigen. Sie kritisieren unrichtigerweise die Punkte unserer Beratung vom 17.06. 43, die unserer Meinung nach dem gemeinsamen Kampf unserer befreundeten Völker gegen den gemeinsamen Feind - die deutschen Besatzer - in keiner Weise im Wege stehen.

2. Wir bestätigen erneut, daß wir die Unterstellung der Abteilungen der sowjetischen Partisanen unter dîe Leitung der polnischen Partisanen „Vostok" kategorisch ablehnen, weil die sowjetischen Partisanen eine ausreichende Anzahl gut ausgebildeter Kommandeure haben, die sich von den Verfügungen der eigenen Sowjetregierung leiten lassen. Wir hatten und haben absolut keine Einwände gegen gemeinsame Kampfhandlungen nach einem im voraus ausgearbeiteten Plan, aber seine Ausarbeitung muß in Anwesenheit eines Vertreters unseres Stabes erfolgen.

3. Sie vertreten die Auffassung, daß sich die sowjetischen Partisanen auf dem polnischen Territorium befinden, ziehen die Linie der sowjetisch-polnischen Grenze entsprechend der Zeit vor dem 1. 9. 1939 und verlangen von uns die Festlegung einer Grenze für Handlungen auf eigene Faust. Wo ist da die Logik gemeinsamer Kampfhandlungen, von der Sie in Ihren Schreiben so viel reden? Beide Seiten müssen sich, wenn sie sich über gemeinsame Kampfhandlungen gegen die Deutschen einigen, darüber im klaren sein, daß sich sowohl die sowjetischen als auch die polnischen Partisanen auf einem von den Deutschen okkupierten Territorium befinden. Deshalb lässt sich die Leitung der sowjetischen Partisanen bei der Stationierung wie auch bei der Verlegung von der Erwägung leiten, wo man dem Gegner den stärksten Schlag versetzen kann, weshalb wir dafürhalten, daß es verfrüht ist und nicht zu unseren Aufgaben gehört, die Grenzenlinie zwischen dem Sowjetstaat und dem polnischen Staat zu ziehen. Das ist Sache unserer Regierungen.

4. In Bezug auf die Lipičanskaja Pušča sprechen Sie eine starke Drohung an unsere Adresse aus und schreiben weiter, daß „das Fehlen einer klaren Antwort zu einem Blutvergießen zwischen Brüdern führen wird“. Unseres Erachtens können nur Repräsentanten eine solche Erklärung abgeben, die den Willen nicht des polnischen Volkes, sondern der Deutschen ausdrücken. Sie vergessen gänzlich, daß die Rote Armee und wir als sowjetische Partisanen Blut vergießen im Kampf gegen die Deutschen für die Befreiung des vom Gegner okkupierten sowjetischen und polnischen Territoriums, also das tun, wozu uns der Vertrag zwischen den befreundeten Völkern der Sowjetunion und Polens verpflichtet. Wir zweifeln daran, daß Sie diese Weisungen von Ihrer Regierung haben, weil Ihre „unveränderte Forderung“, die Lipičanskaja Pušča Ihren Abteilungen zu überlassen, nicht etwa von gemeinsamen Kampfhandlungen, sondern von ihrem Abbruch spricht.

5. Ihre Forderung, Ihnen die von diesem Territorium stammenden Polen unter den Partisanen zu übergeben, können wir nicht erfüllen, weil besagte Polen erklä- 
ren, es komme nicht darauf an, in welcher Abteilung man gegen den Feind kämpfe, und sich weigern, zu Ihnen überzugehen. Zugleich denken wir nicht, daß das ein Grund für Sie wäre, Terrorakte gegen die Familien dieser Partisanen zu verüben.

6. Wir haben vereinbart, und Sie haben dem zugestimmt, daß unsere Partisanen frei Kampfhandlungen durchführen, aber obwohl wir am 23. 06. 43 über Ihren Vertreter die Nachricht über das Vorgehen unserer Gruppen übermittelten, schießen die polnischen Partisanen bis heute auf unsere Partisanen. So wurde in der Nacht vom 27.6. zum 28.6. 43 eine Gruppe etwa $500 \mathrm{~m}$ südlich vom Dorf Mintoviči aus dem Hinterhalt beschossen, wobei zwei Pferde und ein Partisan den Tod fanden. Wir halten das ebenfalls für einen Terrorakt, der gegen unseren Vertrag verstößt. Wir haben vereinbart, daß keine Plünderung der örtlichen Bevölkerung von welcher Seite auch immer vorkommen darf, daß die Plünderer festzuhalten und an ihre jeweiligen Abteilungen zu übergeben sind.

7. Eine Diskussion über den Bürger Miščuk halten wir für überflüssig, denn die Einstellung Ihrer Leitung zu ihm ermöglicht einen unbeschränkten Terror, so daß kein Vertrag gilt und Miščuk bei Begegnungen mit unseren Partisanen auch jetzt auf sie schießt.

Sie ironisieren den Vorfall mit dem Mord an Stankevič, der zusammen mit den Deutschen im Wagen fuhr, wobei ein deutscher Beamter fliehen konnte, Stankevič aber nicht. Wir erklären Ihnen, daß wir auch künftig deutsche Kraftfahrzeuge mit ihren Soldaten nicht etwa halten lassen werden, um genau festzustellen, wer darin sitzt, sondern beim Auftauchen eines Wagens mit deutschen Soldaten gleich zuschlagen.

8. Die Leitung der polnischen Partisanen erklärt, daß „wir jeden Fall einer bewaffneten Aktion gegen die örtliche Bevölkerung, der Agitation gegen uns oder einer Kollision mit unseren Kampfabteilungen als Kriegserklärung auffassen und dementsprechend handeln werden". Unseres Erachtens läuft dieser Punkt voll und ganz der Freundschaft zwischen dem Sowjetvolk und dem polnischen Volk zuwider, und wir zweifeln sehr daran, daß Sie diese Weisung von Ihrer Regierung haben, denn das ist nicht anders einzuschätzen denn als Begünstigung unseres gemeinsamen Feindes, der Deutschen.

Wir haben nie derartige Schritte unternommen, gedenken auch nicht sie zu tun, und werden einzelne Personen, die sich Plünderungen oder Agitation gegen Sie erlaubten, auch weiter standrechtlich verurteilen.

Eine Bestätigung für unsere Erklärung können Sie in der Agitation unserer Presse und auch in unserer Einstellung zur polnischen Bevölkerung sehen.

Alles Gesagte zusammenfassend, stimmen wir voll Ihrer Meinung zu, daß Papierdiskussionen oft fruchtlos sind. Was wir von Ihnen wollen, ist nur eins:

1. dem Mord an unseren schuldlosen Partisanen ein Ende zu setzen; jeden Terrorakt betrachten wir als deutsche Provokation;

2. möglichst bald und ein für allemal gemeinsame Kampfhandlungen zu vereinbaren, was der baldigsten Zerschlagung der deutschen Besatzer und der Befreiung des sowjetischen und des polnischen Territoriums von der Okkupation dienen wird;

3. wir sind kategorisch dagegen, daß die Untersuchung des Mordes an 18 Partisanen ohne Teilnahme unseres Vertreters erfolge, denn wir konnten die Schuld der Getöteten an ihrem Tod nicht feststellen.

Wir bitten um eine Antwort binnen dreier Tage, eine Hinauszögerung der Ant- 
wort wird für uns ein Beweis dafür sein, daß Sie keinen gemeinsamen Kampf gegen die Deutschen wünschen.

Leitung des Stabs der Lenin-Brigade

Oberleutnant

(Matveev)

(Bulat)

F. 3500, op. 4, d. 251, 11. 28-31.

Dokument Nr. $8^{23}$

Artikel aus der illegalen Zeitung „Volksrächer“ [„Narodnyj mstitel'“] über eine Operation, die die Abteilung der Armija Krajowa von Stolbcy zur Zerschlagung der Garnison von Ivenec durchführte (19. Juni 1943)

„Narodny Mscicel“24 (Volksrächer)

Organ des Rajonkomitees Ivenec der KP(b)B

Nr. 8 vom 22. Juni 1943

Die polnischen Partisanen vernichteten die deutsche Garnison der Ortschaft I. Vor wenigen Tagen hat eine polnische Partisanenabteilung unter dem Befehl von M. unter aktiver Teilnahme der Polizeigarnison die deutsche Garnison der Ortschaft I. vernichtet. Am Tage brachen die Partisanen in die Ortschaft ein und töteten zusammen mit den Polizisten, die ihnen Hilfe leisteten, alle Deutschen. 40 deutsche Okkupanten wurden getötet. Die Partisanen steckten die Räumlichkeiten der Gendarmerie und das Munitionslager in Brand, dort wurden rd. 75000 Patronen, 5000 Granaten, 6 Granatwerfer, eine Kanone und eine Menge anderer Munition verbrannt, ein Funkgerät und mehrere Kraftfahrzeuge vernichtet. Erbeutet wurden [...] Gewehre, 3 Kraftfahrzeuge und mehrere Granaten.

Über 100 Polizisten und viele junge Leute aus der Ortschaft I. gingen zu den Partisanen über.

In den darauf folgenden Tagen traten mehrere Dutzend bewaffnete Polizisten und "Selbstverteidiger" aus der deutschen Garnison der Abteilung bei. In die Partisanenabteilung wurde außerdem der katholische Geistliche S. aufgenommen.

F. $4 p, 33 a$, d. $469,1.1$.

23 Übersetzung aus dem Belorussischen.

24 Belorussische Schreibweise. 


\section{Dokument Nr. 9}

Vertrauliches Schreiben I. Ponomarenkos, Sekretär des Zentralkomitees der $\mathrm{KP}(\mathrm{B})$ Belorußlands, an die Untergrund-Oblastkomitees der $\mathrm{KP}(\mathrm{B})$ Belorußlands und den Belorussischen Stab der Partisanenbewegung vom 22. Juni 1943

An die Untergrund-Oblastkomitees der $K P(b) B$ der Oblaste

Belostok, Brest, Baranoviči, Vilejka und Pinsk.

An den Belorussischen Stab der Partisanenbewegung.

Vertrauliches Schreiben

des Zentralkomitees des KP(B) Belorußlands

„Über die militärisch-politischen Arbeitsaufgaben in den westlichen Oblasten der BSSR"

Seit mehr als zwei Jahren führen die Völker der Sowjetunion ununterbrochen einen in der Geschichte beispiellosen Kampf gegen die faschistischen deutschen Besatzer, für die Ehre, Freiheit und Unabhängigkeit der Heimat.

Zusammen mit der an der Front kämpfenden Roten Armee setzt das Sowjetvolk, von einem einheitlichen Willen durchdrungen und um unsere Partei und Regierung zusammengeschlossen, in den Fabriken, Betrieben und Kolchosen, im sowjetischen Hinterland und auf dem vom Gegner zeitweilig besetzten Territorium all seine Kräfte ein, um den Sieg über den Feind davonzutragen und ihn aus unserer Heimat zu vertreiben.

Alle Kalküle der Deutschen, die mit einer geringen Festigkeit der Sowjetordnung und des sowjetischen Hinterlandes, mit einem Zwist zwischen den Völkern unseres Landes rechneten, sind gescheitert. Alle Millionenmassen der multinationalen Sowjetunion haben sich zum Großen Vaterländischen Krieg gegen den Feind, der uns überfallen hat, erhoben. Im Feuer des Kampfes ist die Freundschaft zwischen allen Nationalitäten der UdSSR erstarkt und noch unverbrüchlicher geworden.

Das in einem einheitlichen Nationalstaat wiedervereinigte belorussische Volk kämpft zusammen mit den anderen Völkern der Sowjetunion mit selbstloser Beharrlichkeit und beispiellosem Mut gegen den verhaßten Feind.

Die Deutschen haben Belorußland besetzt, es ist ihnen jedoch nicht gelungen, unser Volk zu unterwerfen, seinen Widerstandswillen zu brechen. Dem Aufruf des Genossen Stalin Folge leistend, hat sich das belorussische Volk zum großen Befreiungskrieg gegen die deutschen Unterdrücker erhoben, um die Unabhängigkeit und Integrität unserer Heimat zu behaupten.

Mit beispielloser Kraft hat sich auf dem vom Feind okkupierten belorussischen Boden eine Volksbewegung entfaltet. Der Partisanenkampf hat die breitesten Bevölkerungsmassen Belorußlands erfaßt. Die belorussischen Partisanen und Partisaninnen sind für den Feind zu einer Bedrohung geworden.

Die militärisch-politischen und organisatorischen Maßnahmen, die das Zentralkomitee und die Kommunistische Partei Belorusslands seit Kriegsbeginn getroffen haben, um die Bewegung zu erweitern, Untergrundorganisationen entstehen zu lassen, die Bewaffnung und die Herstellung von Verbindungen zu organisieren, Organisationsgruppen und Organisatoren der Bewegung zu entsenden u. dgl. m., haben eine gewaltige Rolle bei der Entwicklung der Partisanenbewegung und ihrer organisatorischen Festigung gespielt. Die unerhörten Greueltaten der Deutschen, die mas- 
siven Bestialitäten haben das Volk nicht eingeschüchtert, sondern den Partisanenkampf noch schärfer und erbitterter gemacht, der Partisanenbewegung des Volkes das Gepräge verliehen, die Bewegung der Rächer für die ermordeten, zu Tode gefolterten Frauen und Kinder, Mütter und Väter, Schwestern und Brüder, für die eingeäscherten Städte und Dörfer, das vernichtete Volkseigentum, den Ruin des Volkes zu sein.

Der Befreiungskampf des Volkes gegen die Deutschen wächst überall immer mehr an. Auch in den westlichen Gebieten Belorußlands wird die Partisanenbewegung immer breiter und dringt immer tiefer ein. Neue Bevölkerungsschichten erheben sich zum aktiven Kampf gegen die Okkupanten. Das zeugt von der politischen Geschlossenheit der Bevölkerung der westlichen Gebiete der BSSR als Teil der Sowjetunion, den tiefsten Sympathien für das große russische Volk, dem unversöhnlichen $\mathrm{Haß}$ auf die Deutschen, die ein Regime blutiger Repressalien errichtet haben, und der Bereitschaft der breiten Massen, zu den Waffen zu greifen.

Zugleich muß gesagt werden, daß die Partisanenbewegung in den westlichen Gebieten Belorußlands weniger entwickelt ist. Dafür gibt es mehrere Gründe: die große Entfernung, eine schwächere Aktivität unserer Organisatoren, das Fehlen von konspirativen Parteizentren und eines gut funktionierenden Verbindungsnetzes in vielen Rajons.

Ein derartiges Zurückbleiben in der politischen und organisatorischen Arbeit unserer Partei in den westlichen Gebieten ist nicht hinzunehmen, weil sich aus diesem Grund breite Bevölkerungmassen dem aktiven Kampf gegen die deutschen Okkupanten nicht anschließen. Es ist auch deshalb unduldbar, weil dadurch die polnischen nationalistischen Organisationen ihren Einfluß verstärken können, die schon auf dem Territorium Belorußlands mit ihrer Arbeit für die eigenen imperialistischen Ziele begonnen haben.

Deshalb ist es die wichtigste und dringlichste Aufgabe in der politischen und organisatorischen Arbeit der Parteiorganisationen und Parteiorgane der westlichen Gebiete, den Partisanenkampf gegen die Okkupanten in allen Rajons und Ortschaften Westbelorußlands zu schüren, überall, in allen Rajons konspirative Parteizentren und im Untergrund arbeitende Partei- und antifaschistische Organisationen zu bilden, die politische Arbeit unter der Bevölkerung auf jede Weise zu intensivieren, Zeitungen und Flugblätter herauszugeben.

Das wird den Partisanenkampf tief in das Hinterland der Deutschen, wo sie verwundbarer sind, hineintragen und weitere Millionen Menschen zum aktiven Kampf gegen die Okkupanten mobilisieren.

\section{Aufgaben der politischen Arbeit}

Für eine noch größere Erweiterung der Partisanenbewegung und Einbeziehung breiter Schichten der Werktätigen in den westlichen Gebieten gewinnt eine gründliche politische Arbeit in den Massen entscheidende Bedeutung.

Die Parteiorganisationen und die Partisanenabteilungen müssen in ihrer Arbeit die spezifische Situation in den westlichen Gebieten in Betracht ziehen: die überwiegend aus Einzelbauern bestehende ländliche Bevölkerung der westlichen $\mathrm{Ge}$ biete, was den Deutschen die Möglichkeit gibt, die Privateigentümer-Mentalität zu schüren und der Bevölkerung mit Hinweis auf Kolchosen Angst einzujagen; eine von der unsrigen etwas unterschiedliche Lebensweise der Bevölkerung in den west- 
lichen Gebieten, bedingt durch die langjährige Macht der polnischen Herren; weit verbreitete religiöse Gefühle; die nationalistische Bearbeitung eines gewissen Teils der Bevölkerung durch diverse polnische Untergrundorganisationen, die sie gegen die belorussische Bevölkerung aufhetzen; die feindliche Tätigkeit der Überreste der während der Sowjetmacht zerschlagenen Parteien und Organisationen.

Die politische Arbeit in allen Bevölkerungsschichten der westlichen Gebiete muß die ganze Größe und Bedeutung des Kampfes der Sowjetunion gegen die deutschen Okkupanten für die Freiheit, Ehre und Unabhängigkeit der Völker nicht nur der Sowjetunion, sondern auch der anderen freiheitsliebenden Länder demonstrieren.

Es ist notwendig, der Bevölkerung umfassend die militärische Lage der Sowjetunion, die Festigkeit der Sowjetordnung, die Unvermeidlichkeit des Sieges der Roten Armee und der Niederlage der Deutschen zu erläutern, deren demagogische Propaganda und die neuen Methoden des Betruges an den Massen zu entlarven, die Zuversicht auf den Einzug der Roten Armee anzuerziehen.

Die Leiter der konspirativen Parteiorganisationen, die Kommandeure und Kommissare der Partisanenabteilungen, alle Partisanen und Partisaninnen müssen stets dessen eingedenk sein, daß die Stärke der Bewegung in ständigen Kontakten mit der örtlichen Bevölkerung liegt. Deshalb wird auch die Breite des Partisanenkampfes des ganzen Volkes in den westlichen Gebieten Belorußlands von der richtigen Einstellung der Partisanenabteilungen zur Bevölkerung abhängen.

Es darf zur Kränkung der örtlichen Bevölkerung, zu willkürlichen Handlungen ihr gegenüber überhaupt nicht kommen. Fälle von Marodieren und einer falschen Einstellung zur Bevölkerung müssen durch härteste Maßnahmen, bis hin zur Erschießung, unterbunden werden.

Die Partisanenabteilungen müssen durch ihre Handlungen alle Bevölkerungsschichten davon überzeugen, daß die Partisanenbewegung eine Bewegung des Volkes ist, daß die Partisanen und Partisaninnen die Interessen des Volkes schützen und das Volk gegen jede Ungerechtigkeit verteidigen.

Bei der Organisation, Lenkung und Entwicklung des Volkskampfes müssen die konspirativen Parteizentren und die Partisanenabteilungen davon ausgehen, daß die westlichen Gebiete Sowjet-Belorußlands ein fester Bestandteil des Belorussischen Sozialistischen Sowjetstaates, ein unveräußerlicher Teil der Union der Sozialistischen Sowjetrepubliken sind.

Auf dieses wichtige, grundlegende Element unserer Politik, das von gesamtstaatlicher Bedeutung ist, macht das ZK besonders aufmerksam, weil die polnische Regierung und die nationalistischen polnischen reaktionären Kreise, die der Sowjetunion gegenüber eine feindliche Haltung einnehmen und die historischen Rechte des belorussischen und des ukrainischen Volkes, in ihren Nationalstaaten vereinigt zu leben, nicht anerkennen, den imperialistischen Eroberungsplan verfolgen, die angestammten belorussischen und ukrainischen Lande unter sich aufzuteilen. Die polnische Regierung betrachtet die westlichen Gebiete Sowjet-Belorußlands und der Sowjet-Ukraine als einen Teil des Territoriums Polens, ignoriert die allseits bekannte Tatsache der schon vollzogenen Vereinigung der Belorussen und der Ukrainer in ihren Nationalstaaten und setzt sich für die Fortführung der Politik der Zersplitterung des belorussischen und des ukrainischen Volkes ein.

Dementsprechend gestaltet die polnische Regierung ihre internationale Politik gegenüber der Sowjetunion. 
Den Versuchen der polnischen reaktionären Kreise, der Sowjetregierung diesbezügliche Zugeständnisse auf Kosten der Interessen Sowjet-Belorußlands und der Sowjet-Ukraine abzuzwingen, wurde eine gehörige Abfuhr erteilt, und so gehen sie daran, in den westlichen Gebieten Belorußlands und der Ukraine ein breites Netz von nationalistischen polnischen Organisationen und bewaffneten Abteilungen aufzubauen und in die Untergrundzentren eigene Agenten einzuschleusen; in ihrem Bestreben, neue Positionen unter den Polen zu erobern, schicken sie ihre Emissäre aus, um zu einem bestimmten, ihrer Ansicht nach günstigen Zeitpunkt zur Verwirklichung ihrer imperialistischen Vorhaben auf bewaffnetem Wege bereit zu sein.

Nachrichten aus den Partisanenabteilungen und illegalen Parteizentren sowie den Komitees der antifaschistischen Organisationen sprechen nicht nur davon, daß die polnischen Nationalisten in Städten und Dörfern gewisse Reserven geschaffen und Untergrundorganisationen aufgezogen haben, sondern in einer Reihe von Orten bereits verdeckte Selbstverteidigungsgruppen und eigene Abteilungen organisiert haben, und hie und da sogar Regimenter aufstellen. Zugleich sind sie bemüht, ihr Volk von Aktionen gegen die Deutschen abzuhalten.

In letzter Zeit kommt es vor, daß Vertreter der polnischen nationalistischen Organisationen und Gruppen bei Partisanenabteilungen und Untergrund-Parteiorganisationen zu Verhandlungen auftauchen. Diese Vertreter stellen bestimmte Bedingungen, formulieren im Namen der bestehenden polnischen Zentren offen ihre inhaltlichen Forderungen, daß die von ihnen aus Polen zusammengestellten Abteilungen unabhängig sein müßten, daß die Gebiete, in denen sie ihre Operationen planen, als polnisches Territorium zu betrachten seien und daß bei gemeinsamen Operationen dieser Abteilungen mit sowjetischen Partisanenabteilungen die letzteren dem polnischen Partisanenstab „Vostok“ unterstellt werden müßten. Sie versuchen, unsere Kräfte, das Netz der Parteizentren und -organisationen im Untergrund, Partisanenabteilungen, die leitenden Kader der Partisanenbewegung auszukundschaften, um ihnen einen Schlag zu versetzen.

Vorläufig sind sie bestrebt, offene Zusammenstöße mit uns zu vermeiden, da sie einsehen, daß das Volk im Kampf gegen die Deutschen gewisse gemeinsame Interessen hat. Doch arbeiten sie insgesamt darauf hin, die Kräfte zu sammeln und zu einem offenen Kampf gegen uns bereit zu sein.

Schon jetzt kommt es vor, daß polnische Nationalisten unsere Partisanen ermorden und eigene Agenten zur Subversion in die Partisanenabteilungen einschleusen.

Es ist ferner in Betracht zu ziehen, daß die Deutschen selbst polnische Formationen aufstellen und, die polnischen nationalistischen Organisationen vorschiebend, die Polen gegen die Belorussen aufhetzen werden.

Die Parteiorganisationen im Untergrund und die Partisanenabteilungen müssen es verstehen, sich in ihrer politischen Arbeit unter der polnischen Bevölkerung auf jene Schichten zu stützen, die mit der Sowjetmacht sympathisieren. Es gilt, den Versuchen verschiedener polnischer nationalistischer Organisationen, die Bevölkerung in ihrem Geiste $z u$ bearbeiten, mit all unseren politischen und organisatorischen Maßnahmen entgegenzuwirken.

Hierbei ist folgendes im polnischen Teil der Bevölkerung bekannt zu machen und $\mathrm{zu}$ popularisieren:

1. Äußerungen und Erklärungen des Genossen Stalin darüber, daß die UdSSR an einem starken unabhängigen Polen interessiert ist; 
2. Es muß erläutert werden, daß die Einigung der slawischen Völker ihre Stärke ist und ein Unterpfand der Zerschmetterung des Hitlerismus und der freien Existenz der slawischen Staaten;

3. Am Beispiel der Verräter am polnischen Volk - der Leute wie Beck, Rydz-Smigly, Matuszewski u.a., die das polnische Volk in eine Katastrophe gestürzt haben ist zu zeigen, daß die heutige Politik der polnischen Regierung im Grunde ebenso verräterisch und ein Kapitulieren vor den Hitlerleuten ist, daß sie den Interessen des polnischen Volkes zuwiderläuft;

4. Es ist überall zu erläutern, daß die Deutschen uralte Feinde des polnischen Volkes sind, die mehr als nur einmal in der Geschichte versucht haben, die polnischen Gebiete zu erobern und das polnische Staatswesen zu vernichten;

5. Es ist das Bestehen des „Bundes polnischer Patrioten“ in der UdSSR und der Division „Tadeusz Kosciuszko" bekannt zu machen, die für ein starkes und unabhängiges Polen kämpfen;

6. Es ist die unerträgliche Lage des polnischen Volkes zu beleuchten, das unter dem Joch der hitlerischen Herrschaft leidet.

Bei dieser gesamten Arbeit ist es notwendig, an die polnische Kultur, Lebensweise, Religion, die nationalen Besonderheiten der Polen und ihre Sitten und Gebräuche mit großer Achtung heranzugehen.

Bei der politischen Arbeit unter der Bevölkerung, besonders unter den Polen, ist in Betracht zu ziehen, daß die polnischen Nationalisten den Polen Angst vor Repressalien einzujagen versuchen, die die Sowjetmacht gegen die Polen wegen ihres angeblich untreuen Verhaltens planen soll.

Unsere Aufgabe ist es, den polnischen Nationalisten diese Waffe aus der Hand zu schlagen und die Polen zu überzeugen, daß von Repressalien welcher Art auch immer keine Rede sein kann und daß den ehrlichen Polen kein Haar gekrümmt werden wird.

Das wichtigste und grundlegende Kontingent der Partisanenabteilungen - der bewaffneten Kraft unserer Bewegung - sind heute und in Zukunft die der Heimat selbstlos ergebenen Belorussen, die in den westlichen Gebieten Belorußlands leben.

Die Organisatoren und Leiter der Bewegung müssen vor allem dafür sorgen, daß überall Partisanenabteilungen, Kampfgruppen und Untergrundorganisationen der belorussischen Bevölkerung entstehen. Das Bestehen einer solchen bewaffneten Kraft wird uns die Möglichkeit geben, beliebige Vorhaben und Pläne der nationalistischen polnischen reaktionären Kreise zu vereiteln.

Die Parteikomitees und Parteiorganisationen im Untergrund, die Abteilungskommandeure und -kommissare, alle leitenden Vertreter der Bewegung müssen mit allen politischen und organisatorischen Maßnahmen erreichen, daß in den von den deutschen Okkupanten besetzten westlichen Gebieten Belorußlands nur Gruppen, Organisationen und Abteilungen agieren, die sich von den Interessen der UdSSR leiten lassen.

Das Bestehen von allerlei Organisationen, die durch polnische nationalistische Zentren (in Wilno, Lublin, Warschau u. a.) gelenkt werden, ist als eine widergesetzliche Einmischung in die Angelegenheiten und Interessen unseres Landes zu betrachten. 


\section{Organisationsfragen}

1. In allen Rajons sind Partisanenabeilungen aus örtlichen Bewohnern aufzustellen sowie zu erreichen, daß sich sowohl die gegenwärtig operierenden als auch neu zu bildende Partisanenabteilungen nicht abkapseln, sondern neue Kräfte aus der Bevölkerung für den Partisanenkampf gewinnen.

2. Überall sind konspirative Parteikomitees zu schaffen, die imstande sind, die politische Arbeit in den Massen zu leisten, die Bewegung zu organisieren und zu leiten.

3. Bei der Einbeziehung aller Bevölkerungsschichten in den aktiven Kampf gegen die Deutschen, bei der Erhöhung der Kampfaktivität aller bestehenden und neu zu bildenden Partisanenabteilungen und -gruppen können, besonders in den Gebieten Belostok und Brest, antifaschistische Untergrund-Organisationen, die unter der Leitung konspirativer Parteikomitees arbeiten, eine gewaltige Rolle spielen.

Die Schaffung eines Aufklärungsnetzes antifaschistischer Untergrund-Organisationen aus parteilosen örtlichen Einwohnern, die einander kennen, wird von kolossaler Bedeutung sein für die Festigung der Verbindungen der konspirativen Parteiorganisationen mit den Massen und für die überall zu erreichende Erweiterung des Partisanenkampfes gegen die hitlerischen Okkupanten.

Solche Organisationen, zahlenmäßig nicht stark, von je fünf bis sechs Personen, können überall aufgezogen werden; sie werden eine überaus starke Stütze der konspirativen Parteiorganisationen in der militärischen und politischen Arbeit sein.

Bei unseren Maßnahmen zur Entfaltung eines Netzes der antifaschistischen Organisationen sind unbedingt die Erfahrungen der ehemaligen Mitglieder der kommunistischen Partei und des Komsomol Westbelorußlands auszuwerten, und viele von ihnen müssen zur aktiven Teilnahme an der Schaffung antifaschistischer Organisationen herangezogen werden.

4. Die Untergrund-Parteiorganisationen und Partisanenabteilungen müssen unter der Bevölkerung der westlichen Gebiete verdeckte Partisanenreserven in unbeschränkter Stärke schaffen, um aus ihnen die kämpfenden Abteilungen aufzufüllen bzw. neue Abteilungen und Gruppen zu bilden.

Es darf keinen einzigen Rajon, keine einzige Stadt, kein einziges Dorf geben, wo nicht Kampfreserven der sowjetischen Partisanenbewegung bestehen, die breite Schichten der Bevölkerung umfassen.

5. Die konspirativen Parteiorganisationen und Partisanenabteilungen müssen alle notwendigen Maßnahmen treffen, um unbedingt in alle Städte in den westlichen Gebieten einzudringen und dort eine breite Diversions- und Aufklärungsarbeit zu entfalten.

6. In den Rajons, in denen schon von den polnischen reaktionären Kreisen geschaffene polnische nationalistische Abteilungen bestehen, sind sie erstens beharrlich durch Bildung unserer Partisanenabteilungen und -gruppen zu verdrängen, und zweitens sind Maßnahmen zu treffen, um unsere Agenten in sie einzuschleusen, ihre Verbindungen, Aufgaben, Organisationen, Arbeitsmethoden auszuforschen, die wirklichen Vertreter der polnischen Nationalisten oder der deutschen Aufklärung festzustellen.

Mit Hilfe von uns speziell entsandter zuverlässiger Polen sind derartige Abteilungen und Gruppen zu zersetzen, die werktätigen Polen aber für uns zu gewinnen. 
Von größter Bedeutung für diese Arbeit wird es sein, inwiefern es unseren Genossen gelingt, mehr oder weniger bekannte Polen aus den Reihen der Intelligenz, die in der polnischen Bevölkerung Einfluß haben, für die Arbeit zu unseren Gunsten zu gewinnen.

Es gilt, mit allen Mitteln zu erreichen, daß sich alle werktätigen Polen, die in den westlichen Gebieten Belorußlands leben, in den aktiven bewaffneten Kampf einschalten. Als Sowjetbürger haben sie die Pflicht, im Kampf gegen die faschistischen hitlerischen Horden in einer Front mit allen Völkern des Landes zu stehen.

Die Organisatoren und Leiter der Bewegung müssen die werktätigen Polen sowohl für die schon bestehenden als auch für neu zu organisierende Partisanenabteilungen gewinnen.

In einigen Fällen, wenn es die konkrete Lage diktiert und wenn unser Einfluß hundertprozentig sicher ist, können überwiegend aus Polen bestehende Partisanenabteilungen organisiert werden. Ebenso wie alle sowjetischen Partisanenabteilungen im Hinterland des Gegners müssen sie den Kampf im Interesse der Sowjetunion führen.

In den Rajons, in denen unsere Partisanenabteilungen und Untergrundzentren schon Einfluß haben, sind Operationen der nationalistischen polnischen reaktionären Kreise nicht zuzulassen. Thre Leiter sind unauffällig zu beseitigen. Die Abteilungen sind entweder aufzulösen und die Waffenbasen an uns zu bringen oder, wenn möglich, unter unseren sicheren Einfluß zu bringen, durch Orientierung auf aktiven Kampf gegen die Deutschen zu nutzen, dazu entsprechend zu verlegen und aufzuteilen, um ihnen den Status als selbständige Kampfeinheiten zu entziehen, den anderen großen Abteilungen anzugliedern und einer entsprechenden verdeckten Säuberung von feindlichen Elementen zu unterziehen.

In Betracht zu ziehen ist, daß sich die polnischen Nationalisten gut darauf verstehen, die Konspiration einzuhalten, sehr oft treubrüchig und Meister von Provokationen sind. Bei der Arbeit mit ihnen muß man seine Methoden besonders vorsichtig anwenden, um nicht Provokationen zum Opfer zu fallen. Ebenso wie schon heute werden die polnischen Nationalisten in unsere Abteilungen eigene Vertreter einschleusen, die sich hinter der Maske loyaler Bürgern verbergen, um die Lage, die Vorhaben auszuforschen, das Aktiv festzustellen und unsere Abteilungen zu zerset$z e n$. Solche Leute sind zu entlarven und zu vernichten.

Das ZK macht darauf aufmerksam, daß in diesem Schreiben die grundsätzlichsten Hinweise dargelegt sind. Die konkrete Situation und die Zeit können neue Fragen auf die Tagesordnung setzen. Sie sind an Ort und Stelle zu lösen, wobei von den grundlegenden Interessen und Aufgaben unserer Politik auszugehen ist.

Das Schreiben ist den Kommandeuren, Kommissaren, den Sekretären der Parteiorganisationen der sowjetischen Partisanenabteilungen und dem Komitee der antifaschistischen Organisationen von Brest bekannt zu geben.

Sekretär des Zentralkomitees der $\mathrm{KP}(\mathrm{b})$

Belorußlands 


\section{Dokument Nr. 10}

\section{Funkspruch Nr. 11228 und 11229 des Bevollmächtigten des ZK der KP(b)B und} des Zentralstabes der Partisanenbewegung für die Oblast' Baranoviči vom 4. November 1943 mit dem Gesuch, die AK-Abteilung von Stolbcy entwaffnen zu dürfen

Die in der Oblast' bestehenden polnischen Abteilungen von Milaševskij und andere von den polnischen nationalpolitischen Organisationen angeblich $\mathrm{zu}$ dem Zweck gebildete Gruppen, die von den Deutschen verfolgten Polen zu retten, kämpfen nicht gegen die Deutschen. Derzeit veranstalten sie eine offene konterrevolutionäre antisowjetische Aktion, terrorisieren und ermorden örtliche Einwohner, die den sowjetischen Partisanen helfen, überfallen kleine Partisanengruppen, töten ihre Mitglieder. Gleichzeitig bereiten sie die Mobilisierung von Reserven aus Polen und belorussischen Katholiken vor, um sie zu Truppeneinheiten zusammenzuschließen und diese gegen die Rote Armee zu entsenden, sobald sie sich der alten Grenze nähert.

In der Bevölkerung treiben die Polen Propaganda unter der Parole: „Krieg den Bolschewiki, sie dürfen unsere alte Grenze nicht überqueren!" Die Polen jagen der Bevölkerung mit der Behauptung, beim Einzug unserer Truppen würden „die Bolschewiki die örtliche Bevölkerung erschießen", Angst ein. In einem von uns abgefangenen Brief, der von der polnischen Abteilung Milaševskij kommt, heißt es: „Die Beziehungen zu den Bolschewiki verschärfen sich immer mehr, warten wir ab, was die Moskauer Konferenz über die Ostgrenze beschließt. Zur Zeit kann die Abteilung nicht offen mit bewaffneten Kräften gegen die sowjetischen Partisanen auftreten, weil das für uns ein Risiko ist, sie sind zahlreich."

Vor kurzem ist in der Abteilung Milaševskij ein Offizier aus Warschau, Deckname "Grom", eingetroffen. Die Untergrundorganisation von Novogrudok hat der Leitung der Kirov-Brigade einen von Wagner unterschriebenen Brief zugeschickt, worin es u.a. heißt: „Die sowjetischen Partisanenabteilungen werden als Okkupationsabteilungen betrachtet, die die westlichen Gebiete zu verlassen haben, sonst müßt ihr euch auf ein trauriges Los gefaßt machen."

Bis zu 60 Prozent der Abteilung Milaševskij machen Gutsbesitzer, Offiziere und sonstiges Pack aus. Die Gruppen von Polen, die gegen uns in bewaffnete Kämpfe eintreten, werden von uns vernichtet. Unauffällig beseitigen wir die entsprechenden Leiter der nationalistischen Organisationen. Wir arbeiten an ihrer Entwaffnung. Bitten, eine Operation zur Entwaffnung der Abteilung Milaševskij und Verhaftung der Leiter zu erlauben.

Armjaninov, Černyšev.

F. 3500, op. 23, d. 22, 1. 112. 


\section{Dokument Nr. 11}

Funkspruch des Leiters des Zentralstabes der Partisanenbewegung Nr. 11717 vom 14. November 1943 mit der Erlaubnis, die AK-Abteilung von Stolbcy zu entwaffnen

Funkspruch Nr. 11717 vom 14.11. 43

An Gen. Černyšev

Die Entwaffnung der Abteilung wird erlaubt, aber bitte vorsichtig vorgehen und die Einstellung der Massen zu uns und Ihre eigene Massenarbeit berücksichtigen. Wird ihnen das nicht den Nimbus von Kämpfern verleihen und Ihnen die Sache erschweren? Dennoch hätte die Operation Sinn.

Ponomarenko.

F. 3500, op. 23, d. 23, 1. 18 .

\section{Dokument Nr. 12}

Gefechtsanordnung der Leitung der Stalin-Brigade vom 30. November 1943 über die Entwaffnung der Abteilung in Stolbcy

\section{Streng gebeim}

Expl. Nr. 9

Bruch der Geheimhaltung während der Dauer der Operation ist strafbar.

Gefechtsanordnung

An den Kommandeur und den Kommissar der Ryžak-Partisanenabteilung

der Stalin-Brigade, den 30. November 1943, 15.00 Uhr

Laut Befehl des Chefs des Zentralstabes der Partisanenbewegung beim Hauptquartier des Oberkommandos der Roten Armee Generalleutnant PONOMARENKO und des Bevollmächtigten des Zentralstabes der Partisanenbewegung beim Hauptquartier des Oberkommandos und des ZK der KP(b)B für die Oblast' Baranoviči Generalmajor PLATON ist Punkt 7 Uhr am 1. Dezember 1943 in allen Ortschaften der Rajons die Entwaffnung der Mannschaften der polnischen Legionen („Partisanen“) einzuleiten. Die beschlagnahmten Waffen und Dokumente sind zu registrieren, die Mannschaften der Legionen samt den Waffen in Milaševskijs polnisches Lager beim Dorf Nesteroviči, Rajon Ivenec, zu befördern.

Gegen Widerstand der Legionäre während der Entwaffnung sind körperliche Maßnahmen bis hin zur Erschießung zu treffen.

Im Falle von Schußwaffengebrauch seitens der polnischen Legionäre („Partisanen") sind diese standrechtlich zu erschießen.

Nach Erhalt des Befehls ist dieser sofort als streng geheime Kuriersache in die Operationsgebiete Ihrer Gruppen, Züge und Kompanien zur Ausführung zu verschicken.

Der Befehl ist streng geheim zu halten. 
Für die Preisgabe des Befehls an welche Gruppen auch immer werden die Abteilungskommandeure persönlich zur Verantwortung gezogen.

Kommandeur der Stalin-Brigade

Oberst

Kommissar der Stalin-Brigade

Oberstleutnant

(Gulevič)

Stabschef der Brigade

Oberstleutnant

(Murašev)

(Karpov)

Angefertigt in 10 Expl.

Expl. Nr. 1-zu den Akten.

Expl. Nr. 2, 3- an die Abteilung „Bol'ševik“.

Expl. Nr. 4, 5 - an die Suvorov-Abteilung.

Expl. Nr. 6, 7 - an die Čapaev-Abteilung.

Expl. Nr. 8 - an die Budennyj-Abteilung.

Expl. Nr. 9 - an die Ryžak-Abteilung.

Expl. Nr. 10 - an die Abteilung ....

F. 3603 , op. 1, d. $29,1.84$.

\section{Dokument Nr. 13}

Schreiben des Bevollmächtigten des Zentralstabes der Partisanenbewegung und des $\mathrm{ZK}$ der $\mathrm{KP}(\mathrm{b}) \mathrm{B}$ für die Oblast' Baranoviči mit Hinweisen, wie mit den entwaffneten „Partisanen“ der AK zu verfahren ist (zwischen 2. und

\section{Dezember 1943)}

Gen. Dubov,

die Operation hast Du ausgezeichnet durchgeführt. Das ist sehr gut. Ich erwartete, daß dies ein großes Blutvergießen bedeuten würde. Die Čkalov-Brigade soll mit der Säuberung des Rajons von den weißpolnischen Banden beginnen. Es gilt, die Kavalleriegruppe baldmöglichst zu erwischen. Zwecks Sortierung der ehemaligen polnischen Partisanen sowie gründlicher Untersuchung bilde ich ein Sonderkomitee. Die Leitung sollst Du zusammen mit den Gen. Suchba und Stepčenko übernehmen. Die Untersuchung muß möglichst schnell abgeschlossen werden. Habe bei Gen. Ponomarenko angefragt, wie mit den Anführern zu verfahren ist. Gegenwärtig sind sie streng zu bewachen. Bitte, mir unverzüglich alle Angaben über die Anführer der polnischen Bande mitzuteilen. Es sind Gruppen aufzustellen, die in den Dörfern eine breit angelegte Agitationsarbeit zu ihrer Entlarvung entfalten sollen, damit sie in den Augen der (polnischen) Bevölkerung nicht als Volkshelden dastehen.

Binnen weniger Tage werde ich mit Gen. Donskoj bei euch vorbeikommen. Jetzt muß eine große Gütersendung eintreffen.

Gruß.

Platon.

Einen Gruß an Gen. Surganov.

Die Waffen sollst Du zur Bewaffnung neu gebildeter Abteilungen benutzen. Es wäre ganz gut, eine weitere Abteilung aufzustellen. Die festgehaltenen Polen sind in 
die Abteilung in Gruppen (vorläufig ohne Waffen) aufzunehmen und unseren Kommandeuren zu unterstellen. Einen Teil von ihnen muß man anwerben und nach Hause gehen lassen. Das Pack, besonders die Polizisten, Gutsherren und Kolonisten, ist zu erschießen. Aber das darf niemand wissen. Im Verborgenen handeln.

Deinen Befehl mußt du später aus allen Brigaden zurücknehmen; es war unnötig, sich darin in einem Punkt auf Gen. Platon zu berufen.

F. 1329, op. 1, d. 29, 11. 122, 122 Rückseite.

\section{Dokument Nr. 14}

Funkspruch des Bevollmächtigten des ZK der KP(b)B und des Zentralstabes der Partisanenbewegung für die Oblast' Baranoviči Nr. 12627 vom 4. Dezember 1943 mit der Beschreibung der Operation zur Entwaffnung der AK-Abteilung von Stolbcy

Funkspruch Nr. 12627 vom 4. 12. 43

Im Zusammenhang mit der antisowjetischen konterrevolutionären Tätigkeit der polnischen Abteilung Milaševskij und den in letzter Zeit begangenen Morden an vielen unserer Partisanen wurde am 1. Dezember die Entwaffnung dieser Abteilung vorgenommen. Ihre Kommandeure wurden zu einer Beratung in die Frunze-Brigade beordert und dort verhaftet. Verhaftet sind: Milaševskij, Myščepelka, Abteilungskommandeur Grom, Abteilungskommandeur Ivka, Propagandist Klen, Aufklärungskommissar Val'den und andere Vertreter, die aus Warschau und Wilno gekommen waren. Die Kräfte der Frunze- und der Stalin-Brigade kreisten die Lager der Polen ein. Als die Polen aufgefordert wurden, die Waffen niederzulegen, schrien sie, das sei richtig, sie wollten nicht gegen die sowjetischen Partisanen kämpfen, und baten, sie in die sowjetischen Abteilungen aufzunehmen. Ergebnis: 230 von 310 Personen entwaffnet, 145 Gewehre und Zehnlader, ein schweres Maschinengewehr, 7 leichte Maschinengewehre, 9 Maschinenpistolen und mehrere Tausend Patronen erbeutet. Eine Gruppe von Polen aus dem Dorf Derevno leistete bewaffneten Widerstand. Infolgesessen wurden 10 Polen getötet, 8 verwundet, die übrigen legten die Waffen nieder. Unsere Verluste: zwei schwer Verwundete. Die Kutuzov-Abteilung erbeutete von dieser Gruppe ein leichtes MG, 2 Maschinenpistolen, 32 Gewehre. Unter der Bevölkerung wurde die entsprechende Arbeit geleistet. Ein Teil der Polen ist entlassen worden, den überprüften Teil nehmen wir in unsere Abteilungen auf. Unter unserem Befehl führte Gen. Sidorok die Entwaffnungsoperation durch. Zurzeit verhören wir die Verhafteten.

Bitte uns mitzuteilen, wie mit ihnen zu verfahren ist, wenn kein Flugzeug landet. Unsere Meinung: sie nach dem Verhör zu erschießen.

Černyšev.

F. 3500, op. 23, d. 24, 1. 218. 


\section{Dokument Nr. 15}

\section{Bericht des Kommandeurs der Ryžak-Partisanenabteilung an die Leitung der Stalin-Brigade vom 30. Dezember 1943 über die Tätigkeit der AK-Abteilung von Stolbcy nach der Entwaffnung und Maßnahmen zur Vernichtung der Abteilung}

Kommandeur

der Ryžak-Partisanenabteilung

Hauptmann S. F. Juchovič

30. Dezember 1943
An den Kommandeur der Stalin-Brigade Oberst Gulevič

Bitte Gen. Dubov, Sekretär des Rajonkomitees Ivenec der $\mathrm{KP}(\mathrm{b}) \mathrm{B}$, zu übermitteln.

Heute, da alle Völker der zivilisierten und freiheitsliebenden Länder die beispiellosen Erfolge der Roten Armee bewundern, da Millionen Menschen in den europäischen Staaten, die zeitweilig in die deutsche Sklaverei geraten sind, mit Ungeduld und Freude auf die Rote Armee als die einzige Retterin warten, verüben an dem uns von der Heimat anvertrauten Abschnitt Westbelorußland, insbesondere im Rajon Ivenec, der deutsche Bandit Nurkevič und seine angeblich aus „polnischen“ Legionären bestehende bewaffnete Bande ihre Missetaten und ermorden Dutzende ehrliche sowjetische Partisanen, die für die Befreiung nicht nur des Sowjetvolkes, sondern auch der Völker aller freiheitsliebenden Länder der Welt kämpfen.

Der Bandit Nurkevič kennt weder eine Heimat noch Familie. Je mehr Blut der sowjetischen Partisanen zugunsten des deutschen Faschismus vergossen wird, desto mehr genießt er es.

1. Am 4. Dezember wurden von der Bande Nurkevičs im Gehöft Tolkačev̌šina die mir besonders teuren Partisanen Prokopenko, Golub und Martynov und die Partisanen der Budennyj-Abteilung Petrov und Nisenbaum bestialisch gefoltert und erschossen. Am selben Tag wurden einem Partisanen aus der Budennyj-Abteilung 8 Wunden beigebracht, er liegt jetzt im Sterben.

2. Am 2. Dezember 1943 wurde der Partisan Vasilenkov aus der Abteilung „Bol'ševik" ermordet.

3. In der Nacht zum 7. Dezember ermordete eine Kavalleristengruppe des Banditen Nurkevič im Dorf Kul' bei einem Überraschungsangriff den Abteilungskommandeur, den Stabschef, den Bevollmächtigten der Sonderabteilung und zwei Partisanen der Frunze-Brigade.

4. Im Dorf Židoviči wurden 8 Menschen und all ihr Besitz verbrannt, weil sie nicht zu den Faschisten wollten.

5. Im Dorf Špaki wurde die Familie Sin'kevič vernichtet, weil Sin'kevič selbst Kontakte mit sowjetischen Partisanen unterhielt.

6. Im Dorf Basmany wurde die Familie Žibulja verbrannt, weil der Sohn aus Ivenec fortgegangen war und sich geweigert hatte, den Faschisten zu dienen.

Es könnten noch sehr viele Fakten genannt werden, die davon zeugen, mit welch erschreckender Brutalität die hinterlistige Bande Nurkevič gegen das Volk und die Partisanen vorgeht.

Nurkevič erklärte: „Ich werde die russischen Partisanen schlagen und ihre Fami- 
lien vernichten." Außerdem gibt es eine Vielzahl von Fällen, wo in unsere Abteilungen aufgenommene Partisanen aus den Reihen der ehemaligen polnischen Legionäre, statt ehrlich gegen die Faschisten zu kämpfen, desertiert sind und zugunsten der faschistischen deutschen Armee arbeiten. Zum Beispiel:

1. Aus der Čkalov-Brigade desertierten zwei Legionäre.

2. Aus der Abteilung „Bol'ševik“ desertierten drei Legionäre.

3. Aus dem Vereinigten Rajonzentrum desertierten zwei Legionäre.

Nach mir zur Verfügung stehenden Angaben führt der Bandit Nurkevič zur Verstärkung des Kampfes gegen die sowjetischen Partisanen den Befehl der deutschen Behörden aus, die Bevölkerung zu mobilisieren. In den Dörfern Starinki, Giljaki, Kisluchi u.a. wurde die Mobilisierung bereits durchgeführt.

Deshalb sind von der Bande Nurkevič noch größere Gefahren zu erwarten.

Als alter Partisan dieser Gegend mit genügenden Arbeitserfahrungen schlage ich vor:

1. Streng geheim und in kürzester Zeit mit den besten Kräften der Partisanen unserer Oblast' Baranoviči alle Maßnahmen zu treffen, um die Bande Nurkevič und die Garnison Ivenec zu liquidieren und so die sowjetischen Partisanen vor den örtlichen Faschisten zu sichern.

2. $\mathrm{Zu}$ diesem $\mathrm{Zweck}$ alle faschistischen Elemente nach Ivenec zu verdrängen und von der Heimat Hilfe - einen Bombenangriff auf Ivenec - zu erbitten. Wenn das nicht geht, so könnten wir durch zusätzliche Munitionsversorgung das konterrevolutionäre Nest Ivenec endgültig vernichten.

Kommandeur der Ryžak-Abteilung

Hauptmann

(Juchovič)

Angefertigt in 3 Expl.

Expl. Nr. 1 - an das Rajonkomitee Ivenec der KP(b)B.

Expl. Nr. 2 - an den Stab der Stalin-Brigade.

Expl. Nr. 3-zu den Akten der Ryžak-Abteilung.

F. 1329, op. 1, d. 35, 11. $276 \mathrm{f}$.

\section{Dokument Nr. 16}

\section{Meldung des Chefs der Sonderabteilung der Stalin-Brigade V. Parafenjuk vom} 19. Januar 1944 über Repressalien gegen Familien, die mit der AK kollaborieren

\section{Streng gebeim}

An Oberstleutnant G. B. Donskoj.

Kopie: an den Sekretär des Rajonkomitees Ivenec der KP(b)B Gen. Dubov

Im Gehöft Sutoki, Rajon Ivenec, lebte eine große Familie der vier Brüder Dračinskij, denen die Mühle von Sutoki gehörte. Nach der Blockade der Pušča wurde das Gehöft abgebrannt, die Bewohner verteilten sich auf verschiedene Orte. Einige Männer aus der Familie Dračinskij standen mit polnischen Untergrundorganisationen in Verbindung und leisteten der Abteilung Milaševskij aktive Hilfe. 
Nach der Entwaffnung der Abteilung Milaševskij wurde einer der Dračinskijs, Kazimir Michailovič Dračinskij, als Partisan in die Kompanie des Vereinigten Rajonzentrums Ivenec aufgenommen. Er ist aus der Kompanie desertiert und lebt derzeit in Ivenec (nicht genau festgestellt).

Nach der Entwaffnung der Abteilung Milaševskij kehrte ein Teil der Familie Dračinskij nach Sutoki zurück und spionierte zugunsten der faschistischen polnischen Bande Nurkevič: Sie lieferten Nachrichten über die Bewegung der Partisanen und bauten an verdeckten Stellen zwei Holzbrücken über den Fluß in Richtung auf die Partisanenlager.

Den Brückenbau entdeckten Partisanen der Abteilung „Bol’ševik“. Der Bevollmächtigte der Sonderabteilung dieser Abteilung führte eine Untersuchung durch, bei der die Dračinskijs der aktiven Hilfe für die polnische faschistische Bande Nurkevič und des Brückenbaus abseits der Straßen überführt wurden.

Laut Entscheidung von Gen. Burko wurden Kazimir Vikent'evič Dračinskij, Genrich Vikent'evič Dračinskij, ihrer beider Helfershelfer, der Vostočnik Vasil'ev, und eine weitere Familie erschossen.

Am 13. Januar 1944 hielten die Partisanen der Abteilung „Bol'ševik“ eine Schwester der Dračinskij, Stanislava Michajlovna, geb. 1926, fest, die am 12. oder 13. Januar 1944 im Auftrag von Nurkevič ins Dorf Pil'nica gekommen war. Bei der Durchsuchung wurde bei Stanislava Dračinskij eine Bescheinigung gefunden, ausgestellt am 4.1. 1944 vom Leiter der Sonderabteilung der Dzeržinskij-Brigade Oberstleutnant Altunin. Laut Entscheidung von Gen. Burko wurde Stanislava Dračinskaja als Spionin erschossen.

Sehr sonderbar ist, daß der Leiter der Sonderabteilung der Dzeržinskij-Brigade Personen, die der Sowjetmacht und den Sowjetpartisanen feindlich gegenüberstehen, Papiere ausstellt, wohlwissend, daß die Dračinskaja enge Kontakte mit der Bande Nurkevič unterhielt und daß einige der Dračinskijs schon aus sowjetischen Partisanenabteilungen desertiert waren; und da nimmt er geschäftliche Beziehungen zu offensichtlich feindlich gesinnten Personen auf und versorgt sie mit Papieren im Namen der Sonderabteilung der Brigade.

Ich lasse die Familie Bričkovskij aus dem Dorf Mešiči, Rajon Ivenec, überwachen, die der Sowjetmacht und der Partisanenbewegung gegenüber feindlich gegenübersteht. Der Leiter der Sonderabteilung der Dzeržinskij-Brigade Oberstleutnant Altunin stellt Verbindung mit ihnen her und wirbt eines der Mädchen Bričkovskij (Jadja bzw. Janina) als Informantin an. Einen Zettel dieser Jadja bzw. Janina habe ich Ihnen vorgelegt.

Das oben Dargelegte melde ich Ihnen zur Kenntnisnahme.

ANHANG: Für Gen. Donskoj: Bescheinigung, ausgestellt auf den Namen Dračinskaja, Stanislava, vom 4. 1. 1944, von Oberstleutnant Altunin unterschrieben.

Leiter der Sonderabteilung der STALIN-Brigade

19. Januar 1944.

(Parafenjuk)

F. 1329, op. 1, d. 33, 1. 6 . 


\section{Dokument Nr. 17}

Funkspruch des Chefs des Zentralstabes der Partisanenbewegung Nr. 2339 vom

31. März 1944 mit der Forderung nach Präzisierung der Ergebnisse der am 5. März $1944 \mathrm{im}$ Rajon Lida durchgeführten Operation gegen die AK

Nr. 2339 vom 31.3 .44

An Gen. Gapeev.

Haben Sie überprüft, ob es sich bei der von der Kirov-Brigade am 5. März d. J. im Rajon Lida durchgeführten Operation gegen bewaffnete Gruppen der weißpolnischen Nationalisten, die der Bevölkerung und den Partisanen feindlich gegenüberstehen, tatsächlich um Banden handelte und wer zu diesen gehört? Die Tatsache, daß im Gefecht 47 Personen getötet, dabei aber nur 6 Gewehre und zwei MGs erbeutet wurden, läßt die Annahme zu, daß die Brigade irrtümlicherweise eine Operation gegen Gruppen von bewaffneten Bewohnern durchgeführt hat.

Über jede Frage muß eine genaue und erschöpfende Information vorliegen. Das trifft auch für die Information über die polnischen nationalistischen Gruppen zu. Sonst desorientieren Sie sich selbst und andere. In dieser Hinsicht ist z.B. Ihre Mitteilung über die Ankunft zahlreicher Weißpolen im Rajon Lida unklar; was heißt Ankunft, woher sind sie gekommen, wer sind sie? Welche Kräfte sind das konkret, sind sie bewaffnet? Darüber teilen Sie nichts mit. Deshalb bleibt es unverständlich, warum die ganze Kirov-Brigade nach einem Gefecht, in dem sie mit Ausnahme eines Verwundeten keine Verluste hatte, plötzlich aus dem Rajon Lida in den Rajon Novogrudok zurückweicht.

F. 3500, op. 23, d. 79, 1. 388. 